\title{
Parvovirus B19 and human parvovirus 4 encode a homologous "X protein" in a reading frame overlapping the VP1 capsid gene
}

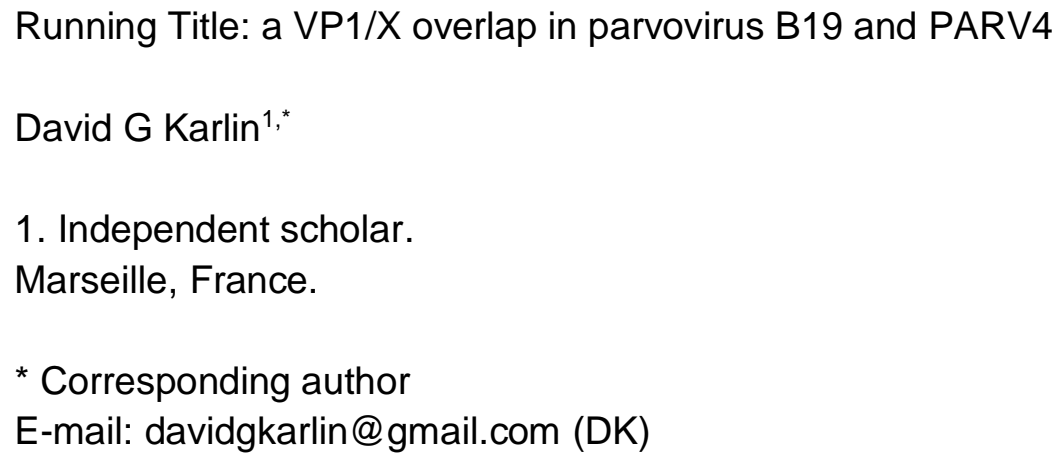
homologous to the ARF1 protein of human parvovirus 4, another suspected protein encoded in a frame overlapping VP1. These findings provide compelling evidence that the $\mathrm{X}$ protein must be expressed and functional. We predict that it contains a predicted transmembrane region. We found that the $\mathrm{X}$ frame contains a potential AUG start codon in parvovirus B19 and in all related species. Yet no currently known viral transcript has the potential to encode the $\mathrm{X}$ protein in a monocistronic fashion. Therefore, the $X$ protein is probably expressed either from an unmapped monocistronic mRNA, or translated by a non-canonical mechanism from the VP1 mRNA or from a short transcript, R3, which has no currently known function. Finally, Synplot2 also detected proteins likely to be expressed from a frame overlapping VP1 in species distantly related to parvovirus B19: porcine parvovirus 2 and bovine parvovirus 3 . 
Parvoviruses are small, non-enveloped viruses (for reviews, see [1-3]). We will focus on two

37 in particular: human parvovirus B19 (B19V) and human parvovirus 4 (PARV4). B19V causes several

38 diseases in humans, such as fifth disease in children, cardiomyopathy, and persistent anemia in

39 immunocompromised persons [4]. PARV4 is not formally associated to any disease, despite

40 suspicions that it may cause encephalitis or accelerate HIV progression [5]. B19V and PARV4

41 respectively belong to the genera erythroparvovirus and tetraparvovirus, which are closely related

42 [2]; other species in these genera infect a variety of mammals (see Fig 1).

43

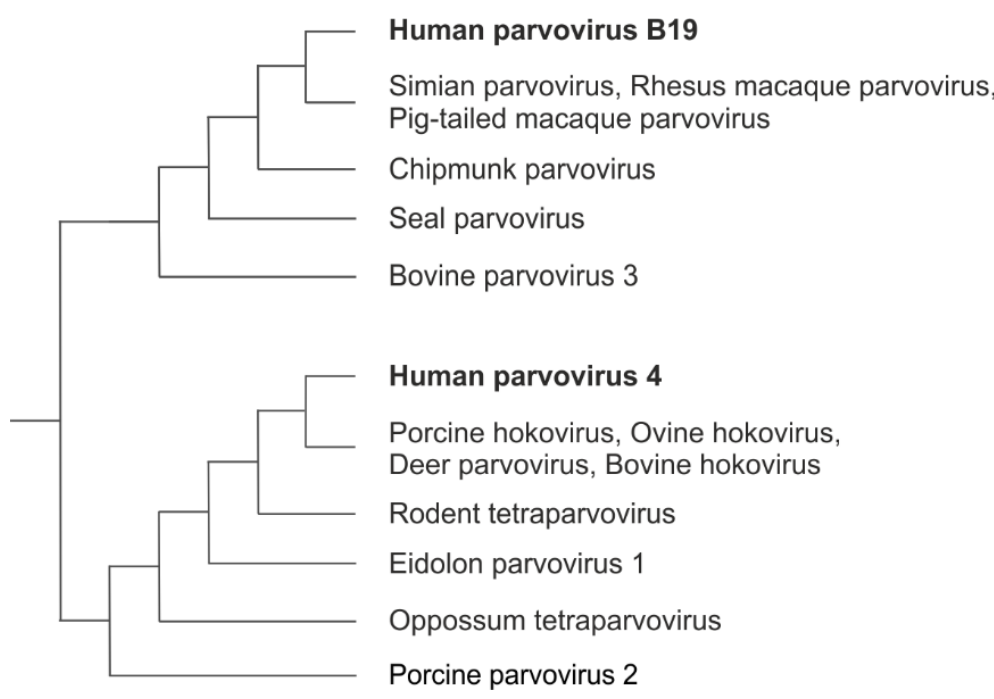

\section{ERYTHROPARVOVIRUSES}

TETRAPARVOVIRUSES

\section{Fig 1: Cladogram of the VP1 proteins of erythro- and tetraparvoviruses}

The genome of every erythro- and tetraparvovirus encodes at least two proteins: the replicase NS1 and the capsid protein, of which at least two isoforms are made: VP1 and VP2 (Fig 2). In B19V, three additional ORFs (open reading frames) have been reported (Fig 2A): the $7.5 \mathrm{kDa}$ ORF, which overlaps the NS1 ORF; the X ORF (which has the potential to code for a $9 \mathrm{kDa}$ protein), which overlaps the VP1 ORF; and the $11 \mathrm{kDa}$ ORF, which partially overlaps the 3' region of the VP1

52 ORF. The expression of the $7.5 \mathrm{kDa}$ protein [6] and of the $11 \mathrm{kDa}$ protein $[7,8]$ have been proven

53 experimentally. In contrast, the expression of the $\mathrm{X}$ protein has never been confirmed in infected

54 cells. A substitution meant to knock out the expression of the X ORF caused no discernable change 
55 in viral replication or infectivity [9], raising doubts on the expression or functionality of the X protein.

56 Likewise, in PARV4, two ORFs overlapping the VP1 ORF have been noticed, but never confirmed

57 experimentally [10]: ARF1 and ARF2 (ARF stands for "Alternative Reading Frame) (Fig 2B).

58

A. Parvovirus B19

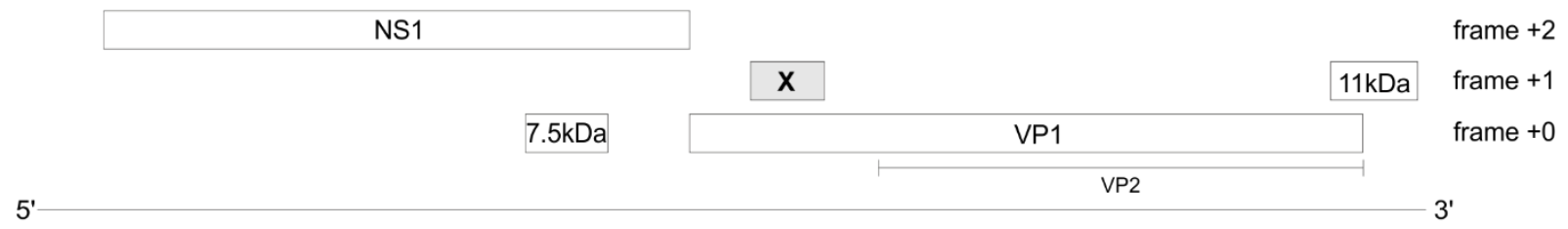

B. Human parvovirus 4

NS1

ARF1 ARF2

VP1

VP2 frame +2 frame +1 frame +0

$5^{\prime}$

\begin{tabular}{|l|l|}
\hline ARF1 & ARF2 \\
\hline & VP1 \\
\hline
\end{tabular}

$3^{\prime}$

\section{Fig 2: B19V and PARV4 encode three suspected protein-coding ORFs}

61 Long, horizontal lines represent the viral genomes. Boxes represent ORFs (Open reading frames).

62 The three ORFs suspected to code for a protein are in grey. The VP2 isoform of VP1 is represented 63 under VP1.

Overlapping ORFs are frequently overlooked in viral genomes [11]. It is possible, in principle,

66 to predict merely from sequence analyses whether a protein is expressed from overlapping ORFs,

67 provided that the protein confers a beneficial function to the virus. In that case, the additional

68 selection pressure that it causes on the sequence of the reading frame that it overlaps results in a

69 lower rate of synonymous codon substitution in that second frame $[12,13]$. Surveys of the B19V and

70 PARV4 genomes detected such a lower rate in the region of VP1 corresponding to the X ORF [14],

71 as well as in the region corresponding to ARF1 and ARF2 [10], but did not provide an estimate of

72 the statistical significance of this reduction. In contrast, the software synplot2 [15] can quantify the

73 probability that an ORF with a reduced synonymous codon substitution rate is expressed and

74 functional. Synplot2 has been successfully used to detect over 15 overlapping ORFs later been

75 confirmed experimentally (e.g. [16-18]). 
We thus chose to use Synplot2 to analyze the VP1 coding sequences of B19V and PARV4.

Synplot2 detected several regions which correspond either to protein-coding ORFs (including that of

the X protein and of ARF1) or to potential functional RNA elements. We compared the sequence

properties of the erythroparvovirus $\mathrm{X}$ protein with that of tetraparvovirus ARF1 and determined that

\section{The VP1 coding sequence of B19V and PARV4 contains regions with reduced synonymous variability}

this work. We collected the coding sequences (CDS) of all genotypes of B19V VP1 available in

GenBank, translated them, aligned their amino acid sequences, and back-translated them to yield a

Table 1. Nucleotide sequences of virus species analyzed in this work.

\begin{tabular}{|l|l|l|l|l|}
\hline Genus & Species & $\begin{array}{l}\text { Common } \\
\text { name(s) } \\
\text { [Abbreviation }]\end{array}$ & $\begin{array}{l}\text { Genbank } \\
\text { genome } \\
\text { accession } \\
\text { number }\end{array}$ & $\begin{array}{l}\text { Boundaries of the } \\
\text { X ORF in the } \\
\text { genome sequence } \\
\text { (in nucleotides) }\end{array}$ \\
\hline Erythroparvovirus & $\begin{array}{l}\text { Primate } \\
\text { erythroparvovirus } \\
1\end{array}$ & $\begin{array}{l}\text { Parvovirus B19 } \\
\text { [B19V] }\end{array}$ & $\begin{array}{l}\text { NC_000883 } \\
\text { 2874-3119 }\end{array}$ \\
\hline Erythroparvovirus & $\begin{array}{l}\text { Primate } \\
\text { erythroparvovirus } \\
2\end{array}$ & $\begin{array}{l}\text { Simian } \\
\text { parvovirus }\end{array}$ & U26342.1 & $2718-2963$ \\
\hline
\end{tabular}




\begin{tabular}{|c|c|c|c|c|}
\hline Erythroparvovirus & $\begin{array}{l}\text { Primate } \\
\text { erythroparvovirus } \\
3\end{array}$ & $\begin{array}{l}\text { Rhesus } \\
\text { macaque } \\
\text { parvovirus } \\
\end{array}$ & AF221122.1 & $2841-3080$ \\
\hline Erythroparvovirus & $\begin{array}{l}\text { Primate } \\
\text { erythroparvovirus } \\
4\end{array}$ & $\begin{array}{l}\text { Pig-tailed } \\
\text { macaque } \\
\text { parvovirus }\end{array}$ & AF221123.1 & $2563-2802$ \\
\hline Erythroparvovirus & $\begin{array}{l}\text { Rodent } \\
\text { erythroparvovirus } \\
1\end{array}$ & $\begin{array}{l}\text { Chipmunk } \\
\text { parvovirus }\end{array}$ & GQ200736.1 & $3031-3228$ \\
\hline Erythroparvovirus & Seal parvovirus & Seal parvovirus & KF373759.1 & $2789-3100$ \\
\hline $\begin{array}{l}\text { Erythroparvovirus } \\
\left({ }^{*}\right)\end{array}$ & $\begin{array}{l}\text { Ungulate } \\
\text { erythroparvovirus } \\
1\end{array}$ & $\begin{array}{l}\text { Bovine } \\
\text { parvovirus } 3 \\
\text { [bPARV3] }\end{array}$ & NC_037053 & $2627-2926$ \\
\hline Tetraparvovirus & $\begin{array}{l}\text { Chiropteran } \\
\text { tetraparvovirus } 1\end{array}$ & $\begin{array}{l}\text { Eidolon helvum } \\
\text { parvovirus }\end{array}$ & NC_016744.1 & $2829-3062$ \\
\hline Tetraparvovirus & $\begin{array}{l}\text { Primate } \\
\text { tetraparvovirus } 1\end{array}$ & $\begin{array}{l}\text { Human } \\
\text { parvovirus } 4 \\
\text { [PARV4] }\end{array}$ & NC_007018.1 & $2937-3140$ \\
\hline Tetraparvovirus & $\begin{array}{l}\text { Ungulate } \\
\text { tetraparvovirus } 1\end{array}$ & $\begin{array}{l}\text { Bovine } \\
\text { hokovirus } 1\end{array}$ & NC_028136 & $2857-3111$ \\
\hline Tetraparvovirus & $\begin{array}{l}\text { Ungulate } \\
\text { tetraparvovirus } 2\end{array}$ & $\begin{array}{l}\text { Porcine } \\
\text { hokovirus }\end{array}$ & EU200677.1 & $2808-3062$ \\
\hline Tetraparvovirus & $\begin{array}{l}\text { Ungulate } \\
\text { tetraparvovirus } \\
5\end{array}$ & $\begin{array}{l}\text { Deer } \\
\text { tetraparvovirus }\end{array}$ & NC_031670.1 & $2766-3020$ \\
\hline $\begin{array}{l}\text { Tetraparvovirus } \\
\left({ }^{*}\right)\end{array}$ & $\begin{array}{l}\text { Ungulate } \\
\text { tetraparvovirus } 3\end{array}$ & $\begin{array}{l}\text { Porcine } \\
\text { parvovirus } 2 \\
\text { [pPARV2]; } \\
\text { Porcine cnvirus; } \\
\text { Parvovirus YX } \\
\end{array}$ & NC_035180 & $\begin{array}{l}\text { No X ORF; } \\
\text { boundaries of the } \\
\text { Z ORF are 2817- } \\
3098\end{array}$ \\
\hline Tetraparvovirus & $\begin{array}{l}\text { Ungulate } \\
\text { tetraparvovirus } 4\end{array}$ & Ovine hokovirus & JF504699.1 & $2855-3112$ \\
\hline Tetraparvovirus & - & $\begin{array}{l}\text { Opossum } \\
\text { parvovirus }\end{array}$ & MG745671.1 & $2862-3092$ \\
\hline Tetraparvovirus & - & $\begin{array}{l}\text { Rodent } \\
\text { parvovirus }\end{array}$ & MG745669.1 & $2960-3217$ \\
\hline
\end{tabular}

99 The main species analyzed here are in bold.

$\left.100{ }^{*}\right)$ The taxonomic classification of these species might need a revision in view of our analyses. 
Synplot2 identified three regions with a statistically significant increase in the conservation of synonymous sites (Fig 3B):

1) The first region spans codons 58-163 of VP1 (see Table 2), and corresponds to the hypothetical X ORF. In all B19V sequences, this ORF is devoid of stop codons in frame +1 relative to VP1 (Fig 1C). A potential AUG start codon overlaps codon 84 of VP1 and is conserved in all B19V sequences, confirming that the X ORF has the potential to code for a protein. As Fig 3A shows, the X ORF is entirely embedded within the region encoding VP1u (the N-terminus of the capsid protein, found in VP1 but not in VP2), and partially overlaps the region encoding the Phospholipase A2 (PLA2) domain of VP1 $[19,20]$. An ORF similar to the X ORF is found in all other erythroparvoviruses (see below for the special case of bovine parvovirus 3). We discuss potential expression mechanisms of the X ORF later.

2) The second region detected by Synplot2 spans codons 185-239 of VP1 (Fig 3B and Table 2), and has not been described yet, to our knowledge. We called it "Y region". It is devoid of stop codons in frame +2 relative to VP1 in all B19V sequences (Fig 3C). However, it lacks a potential AUG start codon. It might thus either be translated through a non-canonical mechanism, or correspond to a functional RNA, rather than a protein-coding frame. RNAz $[21,22]$ could detect no secondary structure in the $Y$ region to support the hypothesis of a functional RNA. The $Y$ region overlaps the region of VP1 located downstream of the PLA2 domain and extends slightly into VP2 (Fig 3A). Other erythroparvoviruses do not contain an equivalent region devoid of stop codons. 3) The third region detected by Synplot2 is located at the very C-terminus of the VP1 CDS (codons 771-782) (Fig 3B). It corresponds to the N-terminus of the $11 \mathrm{kDa}$ protein (Fig 3A), known to be expressed in the +1 frame relative to VP1 from an AUG that overlaps codon 756 of VP1 $[7,8]$. As expected, the region downstream of this AUG is devoid of stop codons in frame +1 relative to VP1 in all B19V sequences except one (accession number KF724386) (Fig 3C). 
A

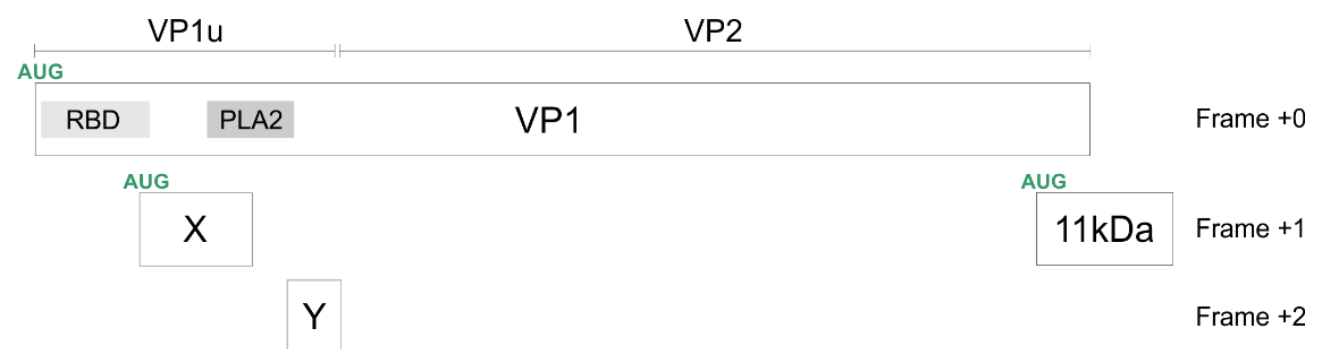

B

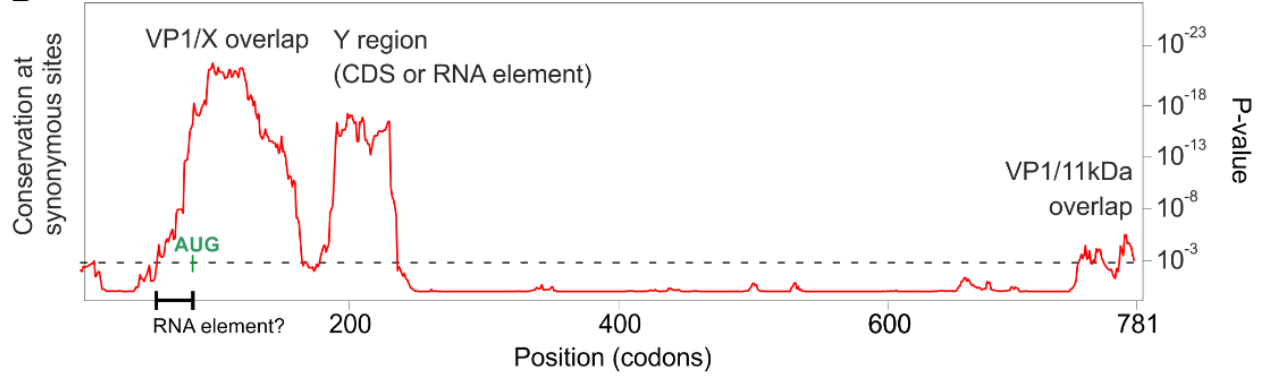

C

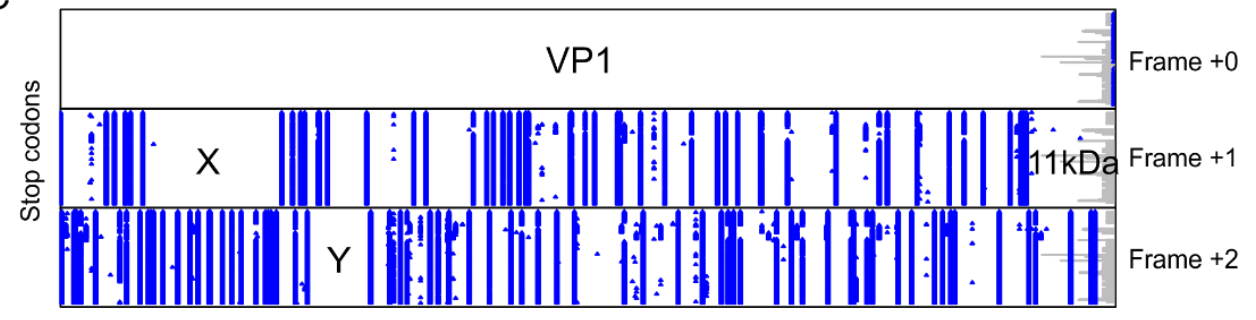

Fig 3. Synplot2 detects 3 regions with significantly lower synonymous-site variability in the

\section{VP1 coding sequence of B19V}

132 A. Representation, to scale, of the VP1 gene and of its overlapping protein-coding sequences

133 (CDS) or functional RNA elements. The potential AUG start codon of the X ORF is shown. PLA2:

134 Phospholipase A2 domain. RBD: receptor-binding domain [23]. VP1u: Vp1-unique region.

B. Sequence conservation at synonymous sites in an alignment of coding sequences of B19V VP1

(121 non-redundant sequences ranging from $87 \%$ to $99 \%$ nucleotide identity), using a 25 -codon

sliding window. The plot corresponds to the P-value calculated by Synplot2 based on the number of substitutions observed and the number expected under a null model (in which synonymous sites evolve neutrally). Regions in which synonymous substitutions are significantly decreased are indicated. The horizontal dotted line shows the significance cut-off value $\left(10^{-3}\right)$. Notice that the first region with a reduced synonymous variability starts markedly before the potential AUG start codon of the $\mathrm{X}$ protein (in green). This region is indicated by a thick line. It might correspond to a functional RNA element, which perhaps facilitates the translation of the $\mathrm{X}$ protein or the splicing of an $\mathrm{X}$ specific RNA transcript (see text). 
C. Position of stop codons (blue) in the 3 potential frames, and gaps in alignment (gray) in the 121

B19V sequences.

Table 2. Boundaries of the regions of VP1 with significantly lower synonymous codon

variability identified by Synplot2 and encompassing potential protein-coding ORFs.

\begin{tabular}{|l|l|l|l|}
\hline Virus name & Region & $\begin{array}{l}\text { Boundaries of the region with } \\
\text { lower synonymous codon } \\
\text { variability in the VP1 CDS }\end{array}$ & $\begin{array}{l}\text { Boundaries of the } \\
\text { corresponding ORF } \\
\text { in the VP1 CDS }\end{array}$ \\
\hline $\begin{array}{l}\text { Parvovirus } \\
\text { B19 }\end{array}$ & X ORF & $\begin{array}{l}\text { Codons 58-163 } \\
\text { (nucleotides 172-489) }\end{array}$ & $\begin{array}{l}\text { Codons 84-166 } \\
\text { (Nucleotides 251-496) }\end{array}$ \\
\hline $\begin{array}{l}\text { Parvovirus } \\
\text { B19 }\end{array}$ & Y region ${ }^{*}$ ) & $\begin{array}{l}\text { Codons 185-239 } \\
\text { (nucleotides 553-715) }\end{array}$ & $\begin{array}{l}\text { Codons 185-230 } \\
\text { (nucleotides 553-715) }\end{array}$ \\
\hline $\begin{array}{l}\text { Human } \\
\text { parvovirus 4 }\end{array}$ & $\begin{array}{l}\text { X ORF } \\
\text { (=ARF1) }\end{array}$ & $\begin{array}{l}\text { Codons 180-263 } \\
\text { (nucleotides 538-789) }\end{array}$ & $\begin{array}{l}\text { Codons 187-255 } \\
\text { (nucleotides 560-763) }\end{array}$ \\
\hline $\begin{array}{l}\text { Human } \\
\text { parvovirus 4 }\end{array}$ & ARF2 & $\begin{array}{l}\text { Codons 294-397 } \\
\text { (nucleotides 880-1189) }\end{array}$ & $\begin{array}{l}\text { Codons 295-379 } \\
\text { (nucleotides 884-1135) }\end{array}$ \\
\hline $\begin{array}{l}\text { Bovine } \\
\text { parvovirus 3 }\end{array}$ & X-like ORF & $\begin{array}{l}\text { Codons 225-289 } \\
\text { (nucleotides 673-867) }\end{array}$ & $\begin{array}{l}\text { Codons 215-315 } \\
\text { (nucleotides 644-943) }\end{array}$ \\
\hline $\begin{array}{l}\text { Porcine } \\
\text { parvovirus 2 }\end{array}$ & Z ORF & $\begin{array}{l}\text { Codons 193-309 } \\
\text { (nucleotides 577-927) }\end{array}$ & $\begin{array}{l}\text { Codons 193-285 } \\
\text { (nucleotides 578-854) }\end{array}$ \\
\hline
\end{tabular}

$153\left(^{*}\right)$ : this region contains an ORF devoid of stop codon, but lacks a potential AUG start codon, and might not code for a protein.

\section{The VP1 gene of PARV4 contains 2 regions with significantly reduced}

\section{synonymous variability, corresponding to ARF1 and ARF2}

described above for B19V. Fig 4B shows that two regions have a highly significant increase in the 
A

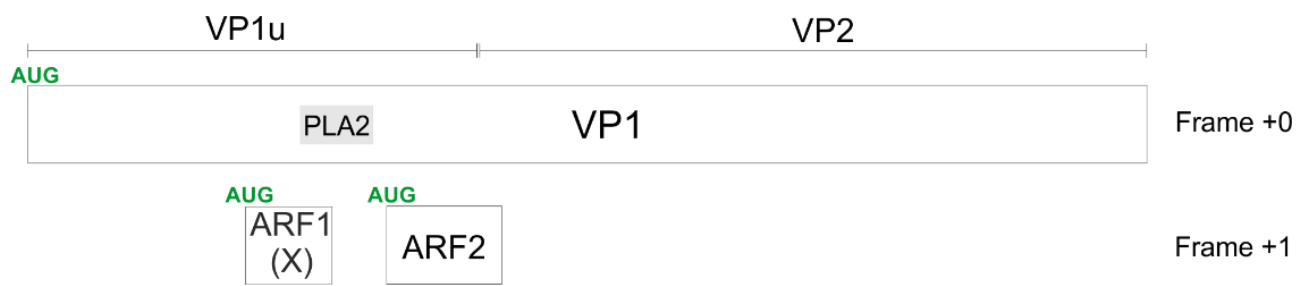

$\mathrm{B}$

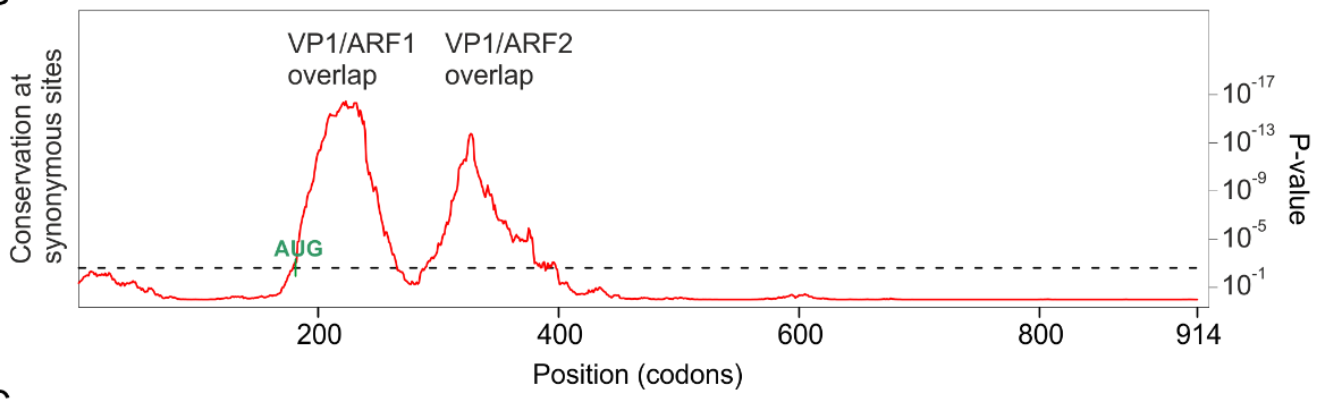

C

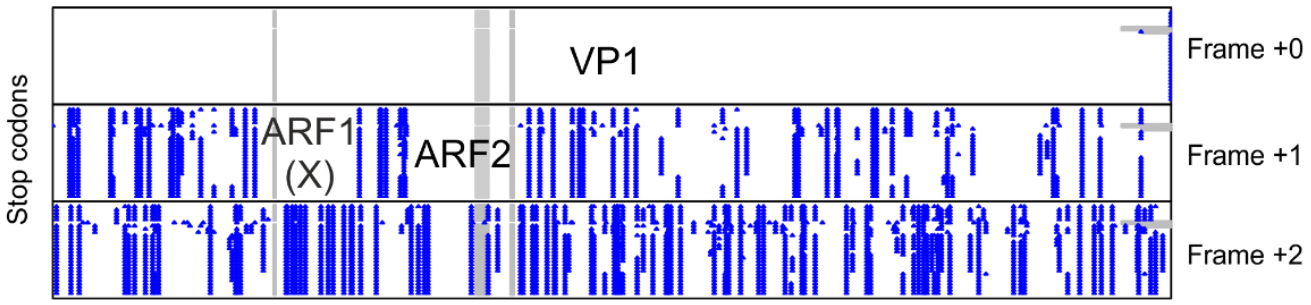

Fig 4. Synplot2 detects 2 regions with significantly lower synonymous-site variability in the

\section{VP1 coding sequence of B19V}

A. Conventions are the same as in Fig 3. The potential AUG start codon of the X ORF is shown.

B. Conservation at synonymous sites in an alignment of coding sequences of PARV4 VP1 (21 nonredundant sequences ranging from $93 \%$ to $99 \%$ identity), using a 25 -codon sliding window in Synplot2.

C. Position of stop codons (blue) in the 3 potential frames, and gaps in alignment (gray) in the 21

1) The first region spans codons $180-263$ of VP1 (Table 2), which corresponds to the hypothetical ARF1 protein [10] (see Introduction). In all PARV4 sequences, ARF1 is devoid of stop codons in frame +1 relative to VP1 (Fig 4B). It has a potential AUG start codon conserved in all

175 PARV4 sequences, overlapping codon 187 of VP1. ARF1 is embedded within the VP1u region, and 176 partially overlaps the PLA2 domain (Fig 4A). An ORF similar to ARF1 was found in all other 177 tetraparvoviruses, with the exception of porcine parvovirus 2 (see below). 
2) The second region detected by Synplot2 spans spanning codons 294-397, and corresponds to the hypothetical ARF2 protein [10] (see Introduction). ARF2 is devoid of stop codons in frame +1 relative to VP1 (Fig $4 \mathrm{C}$ ). It has a potential AUG start codon conserved in all PARV4 sequences, overlapping codon 294 of VP1. The ARF2 frame overlaps the region of VP1 located immediately downstream of the PLA2 domain, and extends slightly into VP2 (Fig 4A). Note that

PARV4 ARF2 and the putative Y protein of B19V cannot be homologous, because they are encoded in different frames relative to VP1 (respectively +1 and 2, compare Fig 4A and Fig 3A). An ORF similar to ARF2 is found only in tetraparvoviruses closely related to PARV4: expression mechanisms of ARF2 later.

of tetraparvovirus ARF1 (Fig 5B). The erythroparvovirus X protein contains a predicted central transmembrane segment (Fig $5 \mathrm{~A}$ ). It is followed by a positively charged region, predicted to be

\section{The $\mathrm{X}$ protein and ARF1 are homologous}

\section{The B19V X protein and PARV4 ARF1 protein have similar predicted} features, in particular a central transmembrane segment

Fig 5 presents multiple sequence alignments of the erythroparvovirus $X$ protein (Fig $5 A$ ) and inside the cytosol ("positive-inside rule" [24]). Therefore, the N-terminus of X, which must be on the other side of the transmembrane segment, is necessarily extra-cytosolic (Fig 5A). In B19V and the three closely related erythroparvoviruses infecting monkeys, the C-terminus of the $\mathrm{X}$ protein is predicted to form a second transmembrane segment (boxed in Fig 5A).

Tetraparvovirus ARF1 has a size and predicted organization similar to that of the $\mathrm{X}$ protein 205 

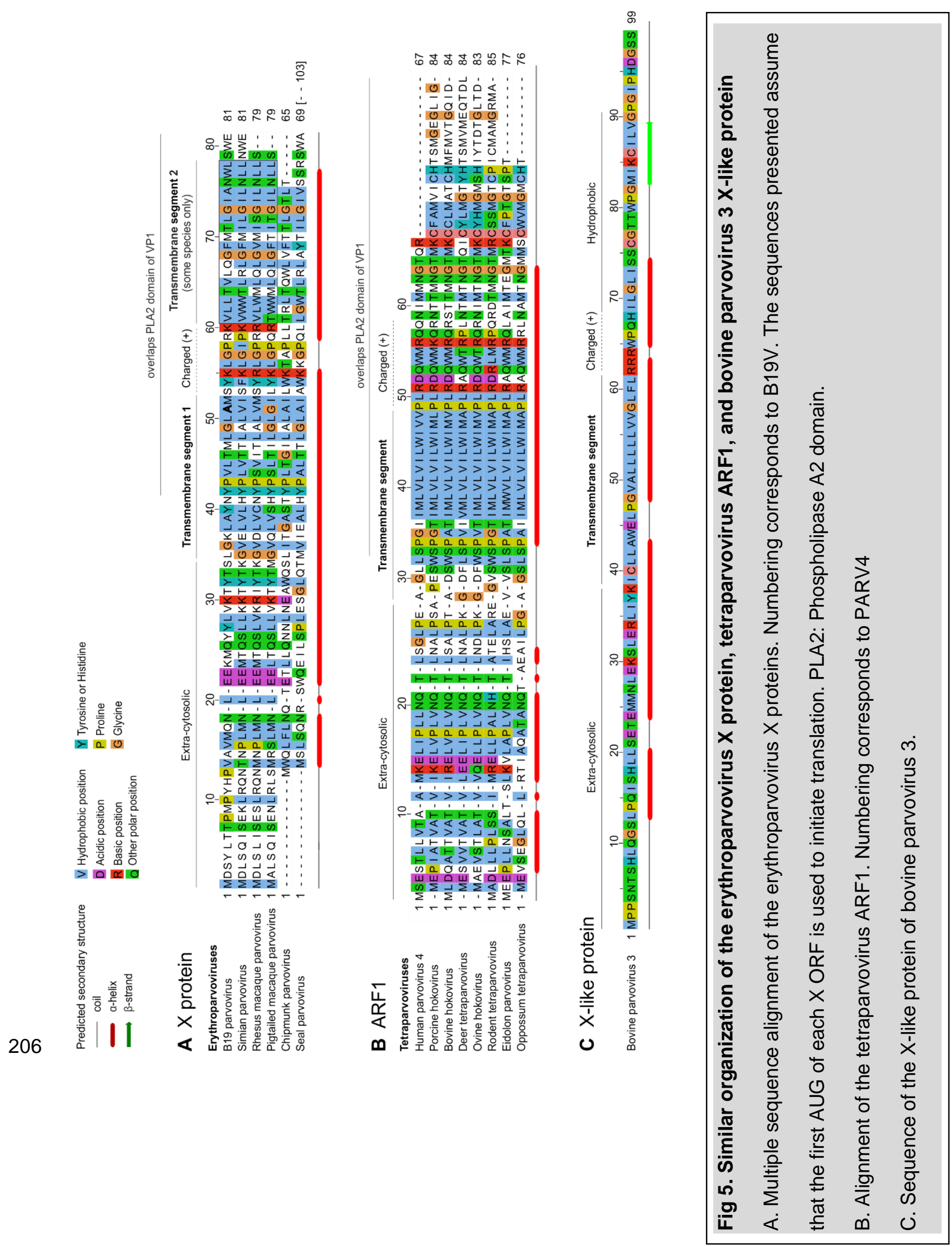
208 The X protein of erythroparvoviruses and the ARF1 protein of 209 tetraparvoviruses are homologous

3 lines of evidence suggest that the erythroparvovirus $X$ protein of and the tetraparvovirus

211 ARF1 protein might be homologous, i.e. share a common origin: 1) they overlap a similar region of

212 the VP1 gene (encoding the PLA2 domain, indicated above the alignments in Fig 5); 2) they are

213 both in the +1 frame relative to VP1 (see Fig $3 A$ and $4 A$ ); 3) they have similar sequence features, as

214 shown above. However, the presence of a transmembrane segment could be explained by

215 convergent evolution [25]. Therefore, to check whether $\mathrm{X}$ and ARF1 are homologous, we examined

216 how their sequences align when based on the much more reliable alignment of VP1, and in

217 particular of its PLA2 domain. Indeed, PLA2 contains numerous strictly conserved amino acids (aas)

$218[19,20]$, which makes its sequence alignment highly reliable.

219 We followed two steps to generate the alignment of erythroparvovirus $X$ proteins and 220 tetraparvovirus ARF1 based on VP1: 1) we converted the aa alignment of the VP1 proteins into an 221 alignment of nucleotide sequences by using TranslatorX [26]; 2) we translated this alignment in the 222 reading frame of $X$ and $A R F 1$, i.e. the +1 frame relative to VP1. This procedure is also described 223 graphically in a previous article [27].

224 The resulting alignment of $X$ and ARF1 is shown in Fig 6 A, while the reference alignment of 225 VP1 is shown below, in Fig 6B. (We only show the PLA2 domain of VP1 because the region 226 upstream is not well conserved). As Fig 6 A shows, the transmembrane segments of $X$ and ARF1 227 align together perfectly. Three aa positions are strictly conserved between $\mathrm{X}$ and ARF1, and one 228 position is semi-conserved (aromatic: Y, W or F). They are indicated above the alignment in Fig 6A. 229 This high degree of conservation, coupled to the fact that erythro- and tetraparvoviruses are closely 230 related genera [2], indicates that $\mathrm{X}$ and ARF1 are most probably homologous. 

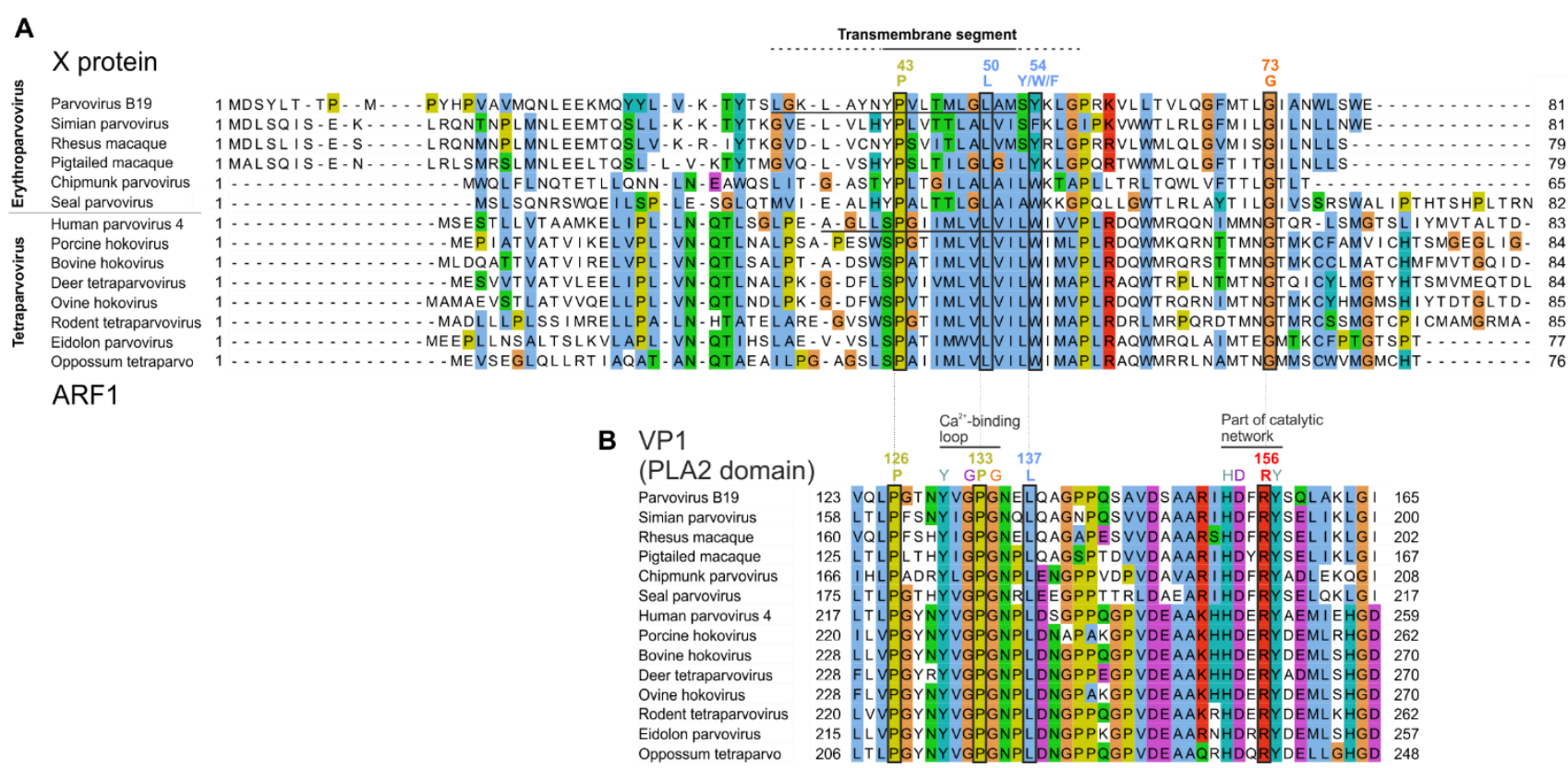

Fig 6 Alignment of all X proteins based on the reliable alignment of the PLA2 domain of VP1

234 Conventions are the same as in Fig 5. Numbering corresponds to B19V.

235 A. Alignment of the $X$ protein of erythro- and tetraparvoviruses, derived from the reference

236 alignment of VP1 presented in panel B. The X alignment was generated from the VP1 alignment by using TranslatorX [26] (see text). Strictly- or semi-conserved aas are boxed and indicated above the alignment. Predicted transmembrane regions are underlined in the sequence of B19V X and PARV4 ARF1. The region that forms a transmembrane segment in both B19V $X$ and PARV4 ARF1 is indicated above the alignment by a thick line; the region that forms a transmembrane segment only 241 in either of these proteins is indicated by a dotted line.

242 B. Alignment of VP1 on which is based the alignment of the X protein in panel A. Only the reliably 243 aligned region of VP1 that overlaps $\mathrm{X}$ is shown; it encompasses the N-terminal part of the PLA2 244 domain. Thin vertical lines show the correspondence between aas encoded by overlapping codons 245 in the X frame (panel A) and in the VP1 frame (panel B). Aas that overlap conserved positions of the $246 \mathrm{X}$ protein are boxed and indicated above the alignment. Other conserved aas involved in functional 247 elements of PLA2 are also indicated. 


\section{Conserved features of the $X$ protein mostly correspond to conserved 251 motifs of the Phospholipase A2 domain of VP1}

We next asked whether conserved sequence features of the $X$ protein correspond to conserved sequence motifs of the PLA2 domain that it overlaps. As Fig 6B shows, the region of

254 PLA2 overlapped by the $\mathrm{X}$ protein contains two conserved features: 1$)$ the putative calcium $\left(\mathrm{Ca}^{2+}\right)$ 255 binding loop (aa 130-134 in B19V); and 2) a region involved in the catalytic network, containing 256 strictly conserved aas H153, D154 and Y157 in B19V numbering $[19,20]$. The conserved features of 257 the $X$ protein correspond to these conserved features of PLA2. First, the transmembrane segment 258 of the $\mathrm{X}$ protein overlaps the $\mathrm{Ca}^{2+}$-binding loop. Second, strictly conserved positions of the $\mathrm{X}$ protein 259 (corresponding, in B19V, to aa P43, L50, G73, boxed in Fig 6A) overlap strictly conserved positions of PLA2, boxed in Fig 6B: P126 and P133 (both within the $\mathrm{Ca}^{2+}$-binding loop), and R156, close to conserved aas of the catalytic network. Likewise, the semi-conserved position of the X protein (Y54 in B19V) corresponds to a strictly conserved position of VP1 (L137 in B19V).

Clearly the PLA2 enzyme is under stringent selection pressure to conserve aas responsible for its catalytic activity. Therefore, one might assume that the sequence conservation within the $X$ protein is dictated by PLA2. However, the sequence of strictly conserved aas of $\mathrm{X}$ is not completely imposed by PLA2. For instance, consider the strictly conserved P133 and G134 in PLA2, which overlap the strictly conserved aa L50 in the $\mathrm{X}$ frame (Fig 6). The strict conservation of this Leucine in the $X$ frame is not imposed by the conservation of $P 133$ and G134, since the dipeptide PG (Proline-Glycine) can be encoded by the nucleotides CCNGGN, in which $\mathrm{N}$ is any nucleotide. The first corresponding codon in the +1 frame relative to PLA2 is therefore $\underline{\mathrm{CNG}}$, which can encode not only Leucine (CTG), but also 3 other aas: Proline (CCG), Glutamine (CAG), or Arginine (CGG). of PLA2. 


\section{The VP1 gene of Bovine parvovirus 3 and porcine parvovirus 2 differs from that of other erythro- and tetraparvoviruses}

\section{Bovine parvovirus 3 may encode a homolog of the $X$ ORF, despite not encoding a Phospholipase A2 domain}

We noticed that one erythroparvovirus species completely lacks the signature of a PLA2 domain in VP1 (as seen using HHpred [28]), unlike all other erythroparvoviruses: ungulate erythroparvovirus 1, also called bovine parvovirus 3 (bPARV3) [29], which is basal to the erythroparvovirus phylogeny [29] (Fig 1).

Synplot2 detects in the VP1 CDS of bPARV3 a region with reduced synonymous variability, in a location similar to the X ORF of erythro- and tetraparvoviruses, i.e. slightly upstream of the VP1/VP2 boundary (Fig 7B). This region corresponds to an ORF conserved in all 4 strains of bPARV3, in frame +1 relative to VP1 (Fig 7C). The reduction in synonymous variability in this region is moderate compared to other erythroparvoviruses (compare Fig 7B with Figs 3B and 4B), but could not be expected to be high, owing to the limited number of nucleotide sequences available (4) and to their limited divergence (they share over $93 \%$ sequence identity). Therefore, the signal detected by synplot2 corresponds to that expected for a protein-coding ORF, which we called "Xlike" protein. 

A

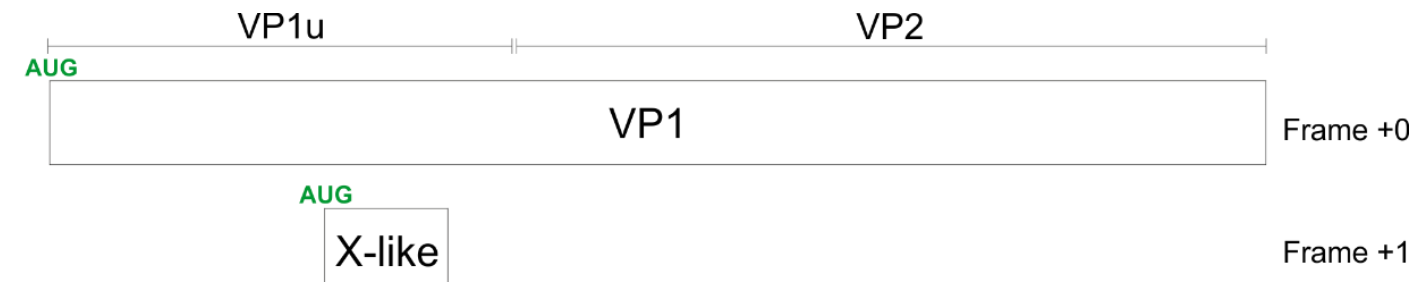

B

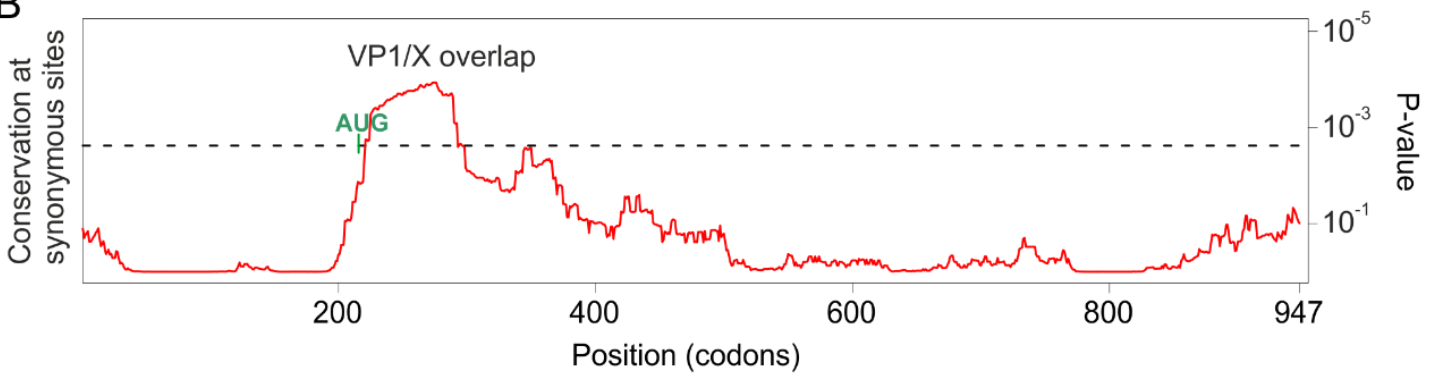

C

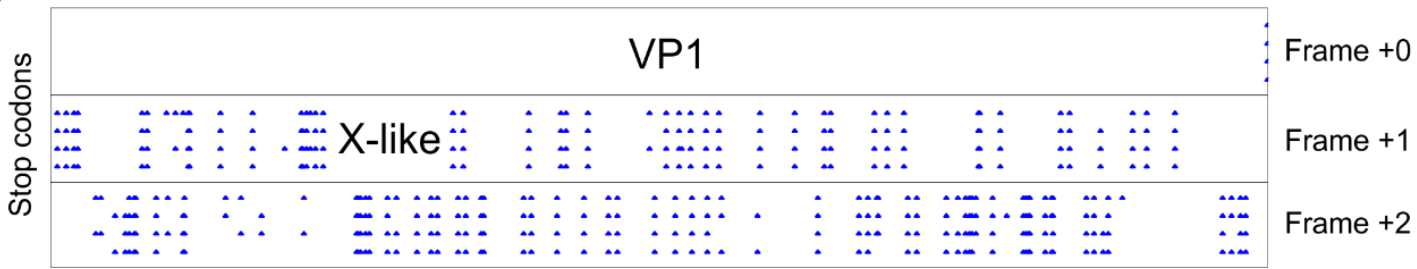

Fig 7. Synonymous-site variability in the VP1 coding sequence of bovine parvovirus 3

A. Conventions are the same as in Fig 3. The position of the VP1/VP2 boundary is approximate.

Bovine parvovirus 3 VP1 does not contain a PLA2 domain, unlike all other erythro- and tetraparvoviruses (see text).

B. Conservation at synonymous sites in an alignment of the coding sequences of bPARV3 VP1 (4 sequences ranging from $93 \%$ to $99 \%$ identity), using a 45 -codon sliding window in Synplot2.

C. Position of stop codons (blue) in the 3 potential frames, and gaps in alignment (gray) in the 4 sequences.

The sequence of the X-like protein is shown in Fig 5C. Its sequence features are strikingly similar to those of the $\mathrm{X}$ protein of erythro- and tetraparvoviruses, such has a similar length (99aas) and organization (central transmembrane segment), suggesting that they might be homologous, i.e. have a common origin. However, because bPARV3 VP1 lacks a PLA2 domain, it is not possible to examine this hypothesis by using the same approach as above, using PLA2 as an anchor to align

311 the X-like protein of bPARV3 with the X proteins. Instead, using MAFFT-add [30], we aligned the sequence of the X-like protein of bPARV3 with the reference alignment of the $\mathrm{X}$ proteins of erythro- 
313 and tetraparvoviruses given in Fig 5. The resulting alignment, presented in S2 Fig, indicates that 2

314 of the 3 aas strictly conserved in erythro- and tetraparvovirus $X$ proteins $(P$ and $L$, both within the

315 transmembrane segment) are also conserved in the X-like protein of bPARV3.

316 Thus, the X-like protein of bPARV3 might be homologous to the $\mathrm{X}$ protein of erythro-and

317 tetraparvoviruses, given their similarity in overall organization and in sequence features. However, it

318 is not yet possible to be certain of this homology in the absence of a PLA2 domain and of

319 sequences intermediate between bPARV3 and other erythroparvoviruses (see Discussion).

321 Porcine parvovirus 2 does not encode an X ORF, but encodes a "Z ORF" 322 overlapping VP1

323 As mentioned above, there is no X-like ORF in porcine parvovirus 2 ( $p$ PARV2) (also called cnvirus 324 [31]), which belongs to the species Ungulate tetraparvovirus 3, and is basal to the tetraparvovirus 325 phylogeny [31] (Fig 1). We examined its VP1 coding sequence with Synplot2. Three regions have a 326 significant increase in the conservation of synonymous sites (Fig 8B): 
A

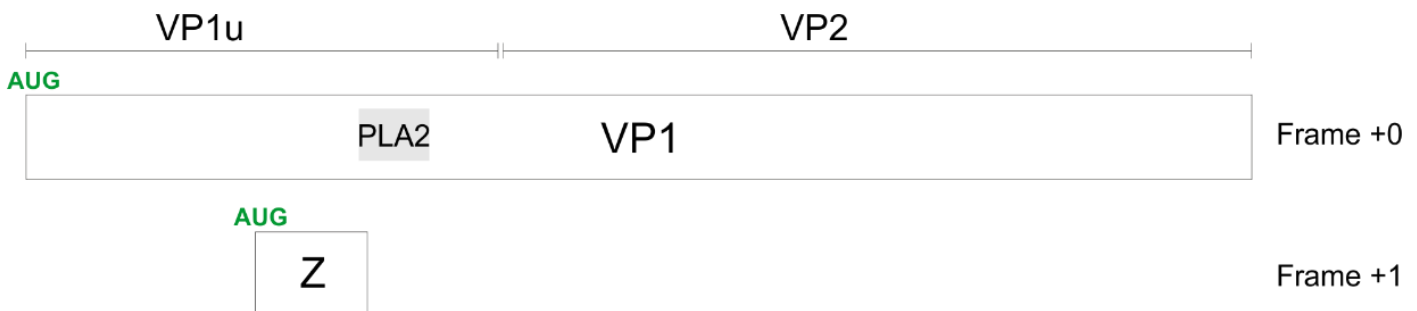

B

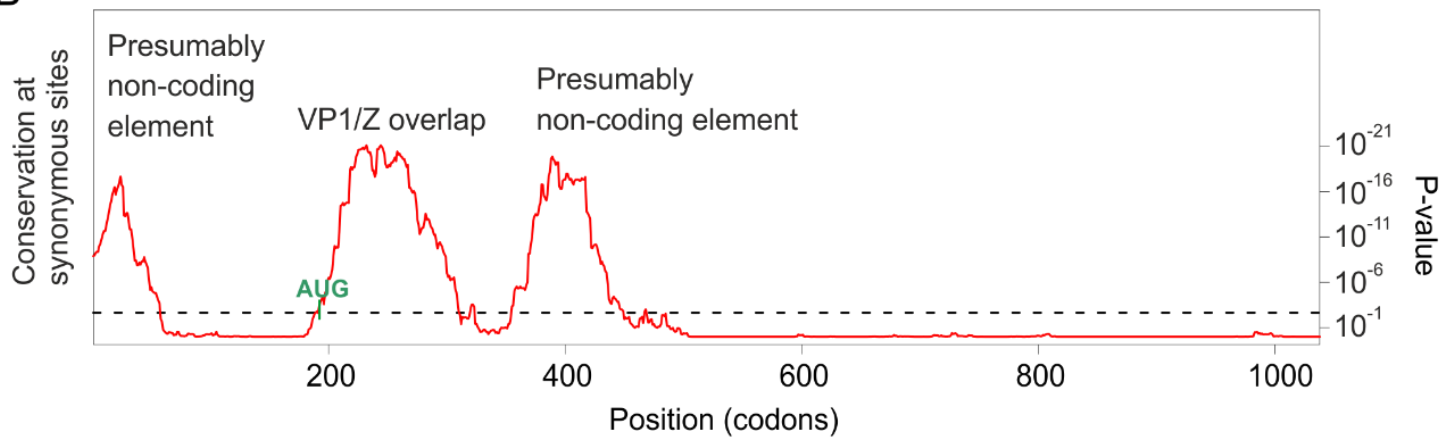

C

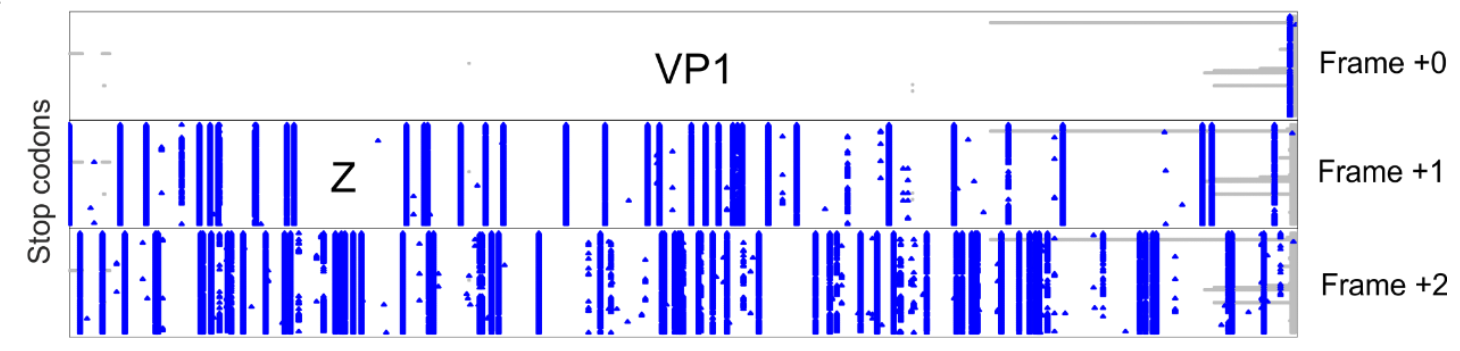

Fig 8. Synonymous-site variability in the VP1 coding sequence of porcine parvovirus 2

A. Conventions are the same as in Fig 3. The position of the VP1/VP2 boundary is approximate.

B. Conservation at synonymous sites in an alignment of the coding sequences of pPARV2 VP1 (90 sequences ranging from $93 \%$ to $99 \%$ identity), using a 45 -codon sliding window in Synplot2. sequences.

1) The first region spans codons $1-57$. It is interrupted by stop codons both in +1 and +2 frames relative to VP1 (Fig $8 \mathrm{C}$ ) and is thus unlikely to encode a protein. It may correspond to an RNA element. RNAz $[21,22]$ could detect no secondary structure in this region.

2) The second region spans codons 193-309. It is devoid of stop codons in frame +1 relative

340 to VP1 (Fig 8C) in all sequences of pPARV2, except one (accession number MK378188). It

341 contains a potential AUG start codon overlapping codon 193 of VP1, conserved in all sequences.

342 Thus, this region probably encodes a protein, which we called "Z protein". The Z ORF overlaps the 
343 region of VP1 upstream of the PLA2 domain and slightly extends into the N-terminus of PLA2 (Fig

$3448 \mathrm{~A})$. The sequence of the $\mathrm{Z}$ protein is shown in S3 Fig. It has a rather low sequence complexity, as 345 estimated by SEG [32], and its $\mathrm{N}$-and C-termini are predicted to be structurally disordered.

3) The third region spans codons 355-449. It is interrupted by stop codons both in frames +1 and +2 relative to VP1 (Fig $8 \mathrm{C}$ ). Thus, it probably corresponds to an RNA element. RNAz [21,22] could detect no secondary structure in this region.

\section{The X protein could either be translated by a non-conventional mechanism or expressed from an overlooked mRNA}

We think that the $X$ protein is probably translated from a standard AUG start codon, but that either this AUG start codon is accessed by a non-canonical mechanism, or the $\mathrm{X}$ protein is translated from a currently unmapped mRNA (presumably thanks to an overlooked splice site). Our reasoning is based on 3 observations:

1) An AUG is found near the beginning of the $X O R F$ in absolutely all erythro- and tetraparvoviruses;

2) No known viral mRNA could encode the $X$ ORF in a monocistronic fashion;

3) The putative AUG start codon at the start of the X ORF is not located in a position favorable to canonical translation.

We detail these observations and our reasoning below.

\section{The X ORF contains a potential AUG start codon in all erythro- and} tetraparvoviruses

In all erythro- and tetraparvoviruses, a potential AUG start codon is found at the beginning of shown). This observation strongly suggests that the X ORF is translated from an AUG start codon. From which viral mRNA (messenger RNA) is it likely to be translated? We discuss this point in the next paragraph. 


\section{No known viral RNA transcript could encode the $X$ ORF in a 373 monocistronic fashion}

A transcription profile is available only in 4 species: B19V, PARV4, simian parvovirus, and

375 chipmunk parvovirus. In these species, there is no monocistronic mRNA that could encode the $X$ 376 protein. We describe their cases below.

1) B19V produces 12 known transcripts by a combination of alternative splicing and

378 alternative polyadenylation [33,34] (for a review, see [4]). Only the transcripts that could encode the

$379 \mathrm{X}$ protein are presented in Fig 9A. 5 transcripts could in principle express the $X$ protein, although

380 these transcripts would be polycistronic (i.e. have the capacity to express at least another protein);

381 they are called R1', R2', R3', R4, and R5 in [4]. As Fig 9A shows, R1' could in principle express 3

382 proteins in addition to X: NS1, 7.5 kDa, and a truncated N-terminal version of VP1. R2' could also

383 express 2 proteins other than X: $7.5 \mathrm{kDa}$ and a truncated N-terminus of VP1. R3', also called the

384 "small" mRNA [35] could encode a truncated N-terminus of VP1, in addition to X. R4 could express

3853 proteins other than $\mathrm{X}: 7.5 \mathrm{kDa}, \mathrm{VP} 1$, and the $11 \mathrm{kDa}$ protein. Finally, R5 could in principle express

386 VP1 and the $11 \mathrm{kDa}$ protein in addition to the X protein. 


\section{A. Parvovirus B19}

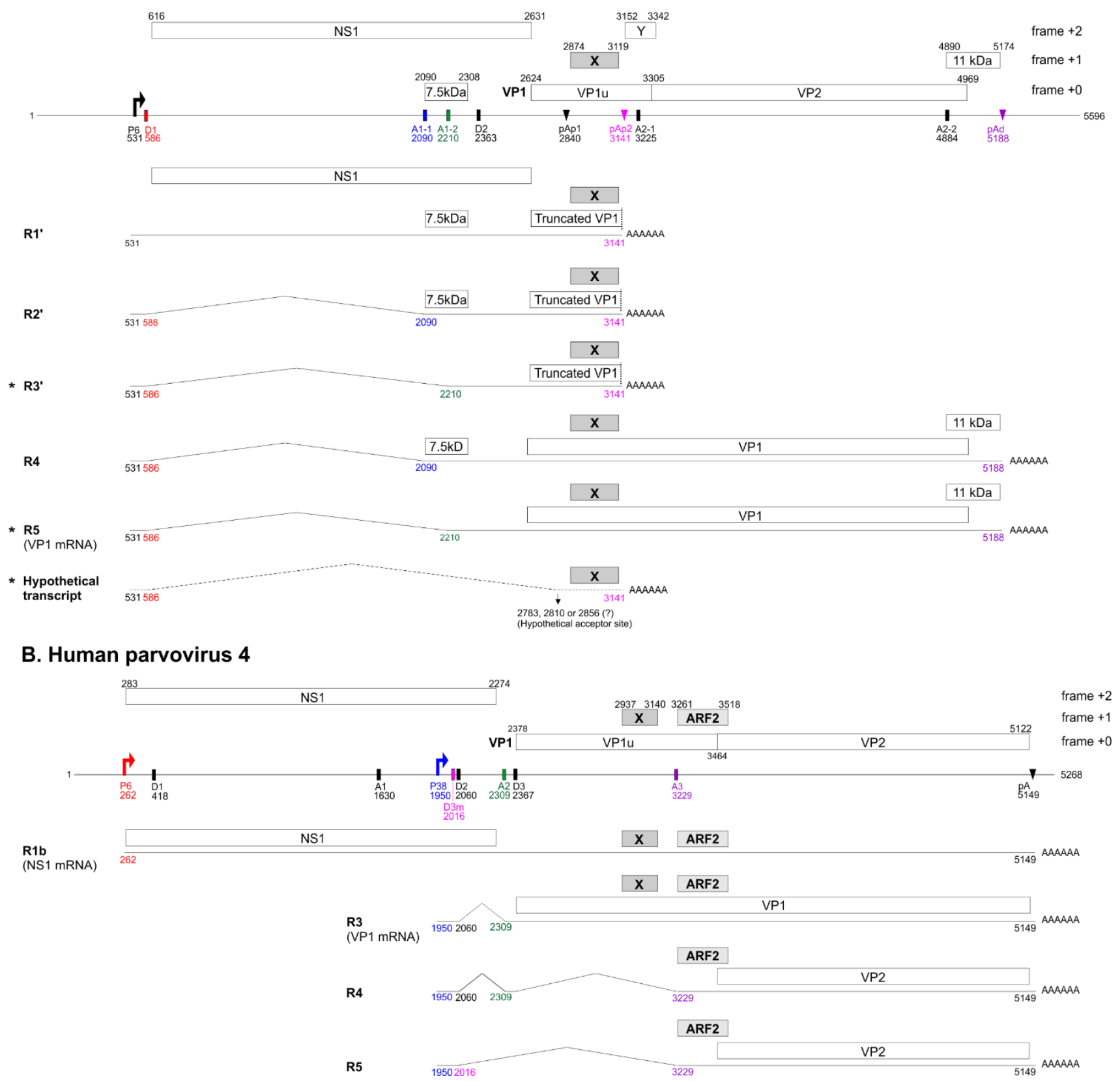

Fig 9. All currently known transcripts that could in principle express the $X$ and ARF2 proteins are polycistronic

391 A. Splicing profile of B19V. Numbering refers to the B19V reference genome. Abbreviations: A1-1, 392 A1-2, A2-1, A2-2: splicing acceptor sites. D1 and D2: splicing donor sites. pAp: proximal poly393 adenylation sites. pAd: distal poly-adenylation site. P6: viral promoter. Transcripts that are most 394 likely to encode the X protein are marked by an asterisk $\left(^{*}\right)$.

B. Splicing profile of PARV4. Numbering refers to the PARV4 reference genome (Table 1). Color coding is not the same as in panel A. Abbreviations: A1, A2, A3: splicing acceptor sites. D1, D2, D3: 
splicing donor sites. pA: poly-adenylation site. P6 and P38: viral promoters. Note that unlike B19V, PARV4 uses only one poly-adenylation site, but two promoters.

2) PARV4 produces 7 known transcripts by a combination of alternative splicing and alternative promoters [36]. Only the transcripts that could encode the $\mathrm{X}$ protein are presented in Fig 9B. Two transcripts could in principle express the X protein: the NS1mRNA and the VP1 mRNA, respectively called $\mathrm{R} 1 \mathrm{~b}$ and $\mathrm{R} 3$ in [36] (Fig 9B). Again, these transcripts would be polycistronic: both could in principle also express ARF1 and ARF2.

3) In simian parvovirus, the X ORF encompasses nt 2718-2963, and could be in principle expressed from at least 4 transcripts (not shown), called R4 to R7 in [37]. Again, none of these transcripts would be monocistronic: they also have the potential to encode full-length or truncated VP1, sometimes fused with other accessory proteins (10 kDa and $14 \mathrm{kDa}$, which are homologous to the B19V $7.5 \mathrm{kDa}$ and $11 \mathrm{kDa}$ proteins, respectively).

4) In chipmunk parvovirus, the X ORF encompasses nt 3031-3228, and could in principle be expressed from at least 3 transcripts (not shown), called R2, R3, and R5 [38]. Again, none of these transcripts would be monocistronic: they are thought to respectively encode NS1, VP1, and a putative protein unique to chipmunk parvovirus called NS2, encoded in a frame overlapping NS1. In summary, no monocistronic mRNA could encode the $X$ protein in the 4 species for which a transcription profile is available. Canonical translation relies on a monocistronic transcript in which the first AUG located in an optimal context is translated (see below; for a review, see [39]).

Therefore, we think 3 hypotheses are likely (Fig 10): 1) the $X$ protein is expressed from an unmapped monocistronic transcript, presumably thanks to an overlooked splice acceptor site; 2) the $X$ protein is translated through a non-canonical mechanism from the VP1 mRNA (transcript R5); 3) the $\mathrm{X}$ protein is translated by a non- canonical mechanism from transcript R3', not currently known to encode a protein. We have marked the corresponding transcripts by an asterisk to the left of Fig 9A. Below we present the arguments that support each of these three hypotheses, focusing on B19V. The hypotheses are presented in the order that seemed most logical to us, and we make no claim regarding the most probable one. 

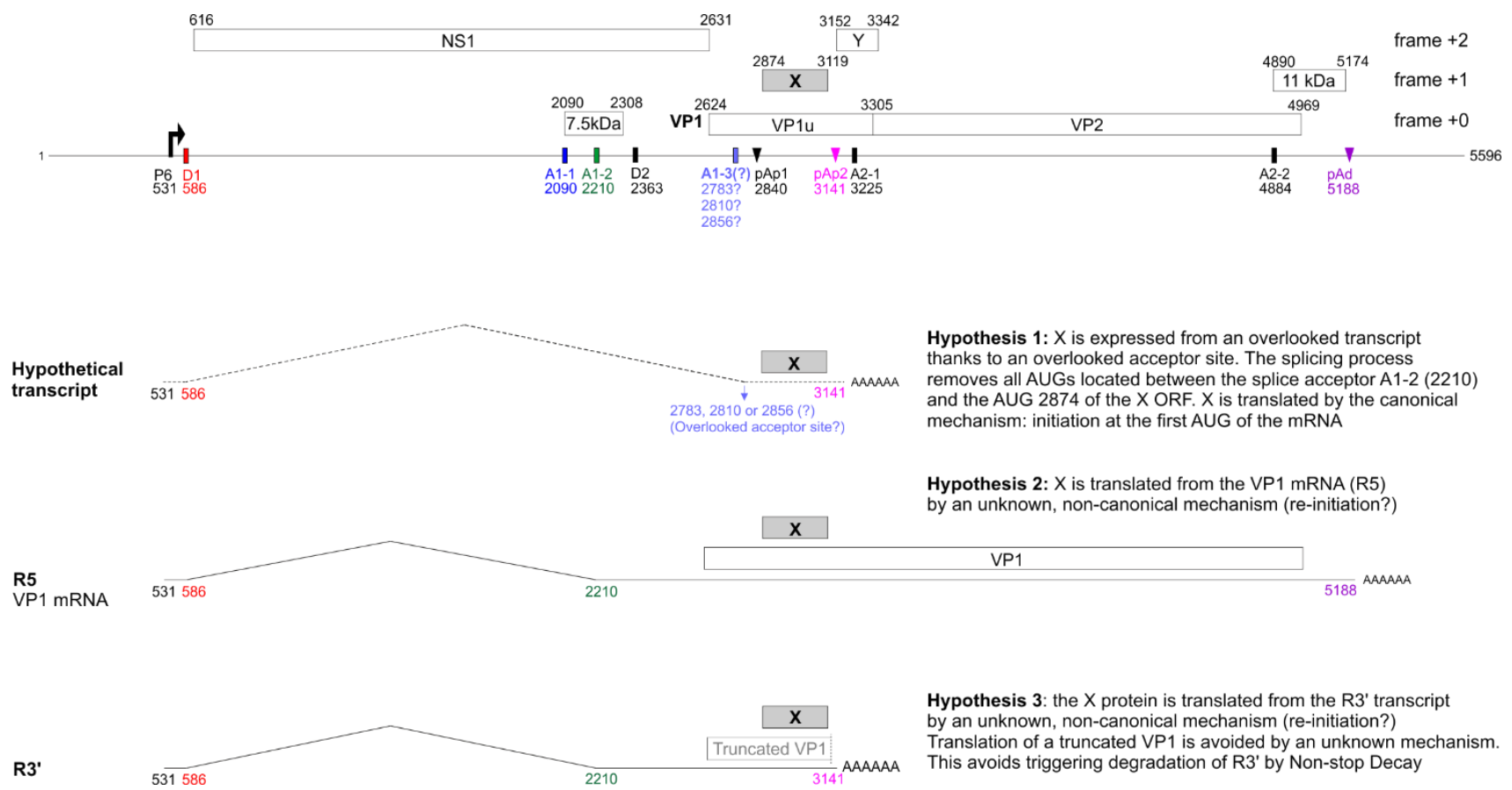

Hypothesis 3: the $X$ protein is translated from the R3' transcript by an unknown, non-canonical mechanism (re-initiation?) Translation of a truncated VP1 is avoided by an unknown mechanism. $53 \overline{158}$ Translation of a truncated VP1 is avoided by an unknown mechar
This avoids triggering degradation of R3' by Non-stop Decay

Fig 10. Three hypotheses about the mechanism by which the B19V X protein is expressed

Conventions are the same as in Fig 9.

First hypothesis: an overlooked splice acceptor site yields a

\section{monocistronic transcript that expresses the $X$ protein}

Two conditions would be required for a splice acceptor site to generate a monocistronic

transcript that encodes the $\mathrm{X}$ protein: 1) this site must be conserved in all isolates of $\mathrm{B} 19 \mathrm{~V}: 2$ ) it must be located in the region between the VP1 start codon and the presumed start codon of the X protein (nt 251-253 of the VP1 CDS).

Canonical splice acceptor sites have the sequence $(\mathrm{C} / \mathrm{U}) \mathrm{AG}$ preceded by a region rich in pyrimidines $(\mathrm{C} / \mathrm{U})$ [40]. We found 3 such potential sites, at nucleotides 158-160, 185-187, and 231233 of the VP1 CDS. (The respective coordinates of the acceptor G in the genomic sequence are 440 transcript that could encode the X protein, since they would splice out both the VP1 AUG start 441 codon and the 4 following AUG codons located upstream of the presumed AUG start codon of the $\mathrm{X}$ 442 protein (in red in Fig 11). 


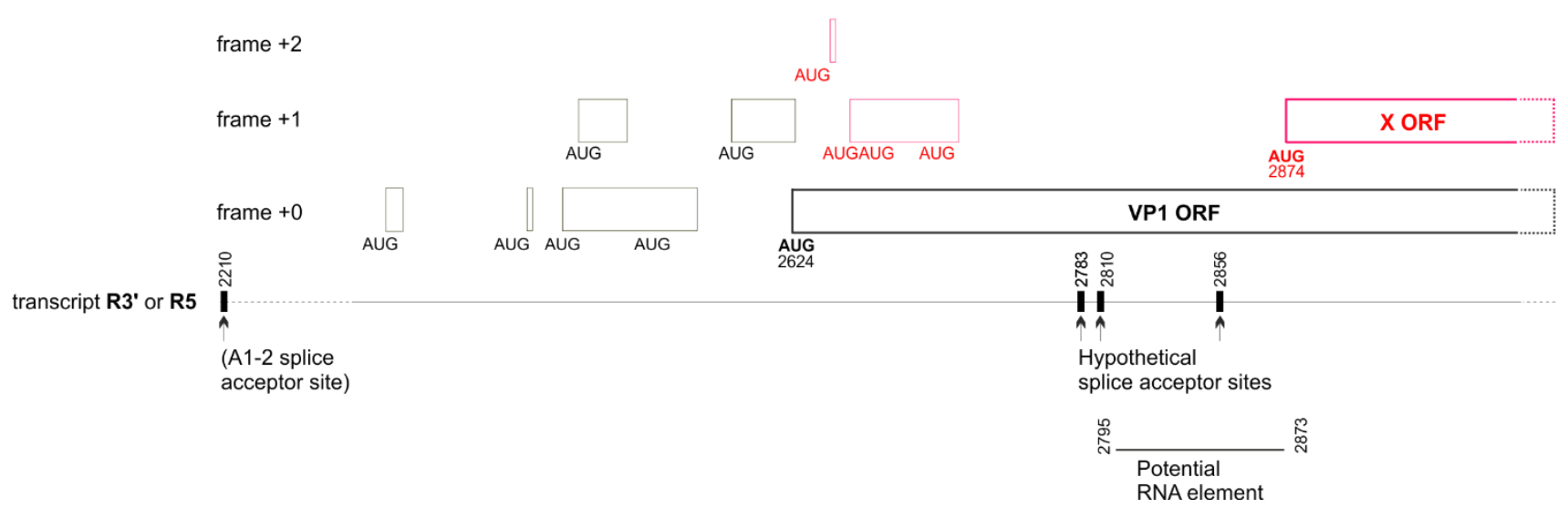

\section{Fig 11. Elements that could influence translation of the VP1 and X ORFs: upstream mini-}

\section{ORFs, potential splice acceptors, and RNA element.}

Thin boxes represent mini-ORFs (that may play a role in regulating the translation of VP1 and X ORFs). The mini-ORFs in black are known to influence the translation of VP1 [41], and might also influence that of the $\mathrm{X}$ protein. The mini-ORFs in red are expected to influence the translation of the X protein but presumably not that of VP1. The potential RNA element corresponds to the region with a decreased variability at synonymous sites upstream of the X ORF (see text and Fig 3B).

\section{Interestingly, these potential splice acceptor sites are located near, or in the region that has} a decreased synonymous variability immediately upstream of the X ORF (Fig 3B), in nt 172-250 of the VP1 CDS (see Table 2). This region might play a role in facilitating splicing at one of these sites, which would explain its decreased variability. We have represented it as a "potential RNA element" in Fig 11. Such RNA elements sometimes have a peculiar secondary structure, but we could not detect an RNA structure in this region using RNAz [21,22].

We made no further effort to look for potential overlooked splice acceptors in other eythroand tetraparvoviruses, since we present these observations on B19V as a starting point to guide experimental approaches.

\section{Second hypothesis: the $X$ protein is translated from the VP1 mRNA by a non-canonical mechanism, such as re-initiation}

In vertebrates, two main factors influence canonical translation from an AUG codon: 1) the strength of the "Kozak sequence" surrounding it [42] (we present Kozak sequences and their 
467 degrees of strength in the Methods); and 2) the position of the AUG codon in the mRNA. In general, 468 the first AUG with an optimal Kozak sequence is used to initiate translation, but many exceptions 469 are known. For instance, a downstream AUG can also initiate translation thanks to a mechanism 470 called "leaky scanning", particularly if the first AUG has a weak Kozak sequence and the 471 downstream AUG has an optimal Kozak sequence (for a review, see [39]). In certain cases, a downstream AUG can initiate translation even if it is separated from the 473 first optimal AUG by intervening AUGs, thanks to a mechanism called "re-initiation" (for a review, 474 [41]). For instance, in B19V, the VP1 AUG codon is preceded by 7 upstream AUG codons that form 475 mini-ORFs (Fig 11) and is accessed by re-initiation after having first initiated translation at some of 476 these mini-ORFs [43]. Note that the presence of these 7 upstream AUGs severely decreases the 477 translation level of VP1 [43].

In principle, the B19V X ORF might likewise be translated from the VP1 mRNA by re-

479 initiation, since it is separated from the VP1 AUG start codon by 4 AUGs (Fig 11). However, the 480 efficiency of translation would presumably be very low [41]. Translation of the X ORF might be 481 facilitated in B19V by the fact that the AUG start codon of the X ORF has a strong Kozak sequence 482 (see Methods), GUCAUGG, contrary to that of VP1, which has a weak Kozak sequence, 483 AUUAUGA. Interestingly, in B19V, the 77 nucleotides upstream of the presumed AUG start codon 484 of the X ORF (nt 172-250 of the VP1 CDS, see Table 2) have a significantly reduced variability in synonymous codons (see Fig 3B). This region with reduced variability might be a regulatory RNA 486 element that would enhance the translation of the $\mathrm{X}$ protein.

For all erythro- and tetraparvoviruses, a similar scenario is possible (translation of the $\mathrm{X}$ 488 protein from the VP1 mRNA by a non-canonical mechanism such as re-initiation). Indeed, in all 489 species, the potential AUG start codon of the X ORF is separated from the VP1 AUG start codon by 490 intervening AUG codons. We detail briefly the case of PARV4: both the AUG start codon of VP1 491 and the potential AUG start codon of the X ORF (nt 560-562 of the VP1 CDS) have a weak Kozak 492 sequence (GCA $\underline{A U G C}$ and CAGAUGU, respectively). They are separated by 9 AUG codons, i.e. 493 much more than in B19V (4 AUGs). In contrast to B19V, the position of the potential AUG start 
494 codon of the X ORF of PARV4 corresponds almost exactly to the start of the region with decreased 495 synonymous variability (see Table 2 and Fig 4B).

\section{Third hypothesis: the $X$ protein is translated from the small RNA, made} monocistronic by a mechanism preventing translation of a truncated VP1

In B19V, translation of a truncated form of VP1 from the R1', R2' or R3' transcripts would probably trigger their degradation by a mechanism of "Non-stop decay" [44], since they are devoid of a stop codon for VP1 (Fig 9A). It is thus reasonable to think that translation of a truncated VP1 is probably prevented somehow in the cell. In transcripts $\mathrm{R} 1$ ' and $\mathrm{R} 2$ ', this translation might be naturally prevented by the fact that the VP1 ORF is located downstream of other translated ORFs. However, in R3', translation of the VP1 ORF is presumably prevented by a specific mechanism. of $\mathrm{X}$ from this transcript would still require a non-canonical mechanism, such as re-initiation, since the putative AUG start codon of the X ORF is preceded by 12 AUGs in the R3' transcript (Fig 11).

\section{PARV4 ARF2 might be expressed by leaky scanning from the} VP2 mRNA

513 beginning of the ARF2 ORF in all isolates of PARV4, porcine hokovirus, ovine hokovirus, and deer

514 tetraparvovirus (S1 Fig). In bovine hokovirus however, this methionine codon is immediately

515 followed by a stop codon (S1 Fig). A potential start AUG codon, conserved in all bovine hokovirus

516 isolates, is found 36 nucleotides downstream, but if it were used to initiate translation, bovine

517 hokovirus would encode an ARF2 amputated of 13 aas that are well conserved in other species. In

518 summary, the first AUG codon is probably used to translate ARF2, except in bovine hokovirus, in

519 which ARF2 might be translated by another mechanism, might be translated in a shorter version by

520 a downstream AUG, or not be translated.

$521 \quad$ From which transcript is ARF2 expressed? In PARV4, 4 transcripts could in principle express

522 it. Following the nomenclature of [36], they are called R1b (the NS1mRNA), R3 (the VP1 mRNA), 
523 R4 and R5 (which both have the capacity to express VP2 in addition to ARF2) (Fig 9B).

524 Interestingly, in the R4 and R5 transcripts, the potential AUG start codon of ARF2 is located 525 upstream of the VP2 AUG start codon. It is thus possible that ARF2 be translated as the "primary" 526 product of the R4 and R5 transcripts, whereas VP2 would be expressed by leaky scanning [39]. 527 Both the ARF2 and VP2 AUG have a weak Kozak sequence, making it hard to predict their relative 528 expression levels in this scenario.

Sequence analyses provide evidence that the $X$ protein must be expressed and have a crucial function

The X ORF was noticed as early as 1986 [45], but has truly lived to its name, since no experimental support has ever been provided for its translation or function in infected cells. Indeed, substituting its presumed start codon by a stop codon had no effect on replication, infectivity, or capsid production in cells permissive for B19 [9].

In contrast, earlier sequence analyses provided support for the translation of a functional product of the X ORF, by detecting a decrease in synonymous codon variability in the region of VP1

540 that it overlaps [14]. Here we quantify this reduction, using Synplot2, and show that it is highly

541 significant. In addition, we show that the X ORF is conserved not only in all erythroparvoviruses but 542 also in the closely related tetraparvoviruses (in which it is called ARF1 [10]). Given the high rate of 543 evolution of viruses, the conservation of the X ORF in two genera provides additional evidence, 544 altogether compelling, that it must be expressed and play a crucial function.

Why would the X protein have escaped detection for so long? A first hypothesis is that it

546 could be produced only at low levels. This hypothesis fits well with our observations about its

547 potential mechanism of expression: on the one hand, if the $\mathrm{X}$ protein is translated from an

548 overlooked transcript, this transcript must be expressed at low levels to have escaped detection. On

549 the other hand, if the $X$ protein is translated by re-initiation, its translation would be expected to 550 occur at low levels [41]. 
A second hypothesis is that the $X$ protein could be expressed only in certain conditions or

552 cell types (B19V being extraordinarily narrow in the range of cells it infects [4]). However, a study

553 showed that it can be expressed in a wide variety of cells (permissive, semi-permissive, or non-

554 permissive) from a plasmid [46]. Therefore, its absence of detection so far might be caused by its

555 expression being restricted to a certain time period and/or certain conditions of infection, rather than 556 to a certain type of cells.

557

Finally, the low expected size of the X protein $(9 \mathrm{kDa})$ could have prevented its detection in 558 standard protein detection experiments.

\section{Experimental studies of the $X$ protein provide very few clues}

Although there are no data regarding the $\mathrm{X}$ protein in infected cells, two experimental studies

provide some hints about this protein. The first relies on indirect evidence. A genomic clone of

B19V, pB19-FL, does not produce infectious virus [47]. A comparison with other infectious genomic

clones flagged 3 substitutions which were unique to pB19-FL, and might thus be responsible for its lack of infectivity. One of these, A51V (in bold in Fig 5), occurs in the X protein, within its predicted transmembrane segment. The 2 other substitutions occur within NS1 (F526L) and VP1 (E176K, located in the C-terminus of the phospholipase A2 (PLA2) domain, not visible in Fig 6). The substitution within VP1 is only in part responsible for the lack of viral infectivity, and thus it is possible that the substitution A51V is also in part responsible for it; this was not tested in the study [47].

The second study [48] reported that the X protein transactivated the P6 viral promoter (which 572 controls the expression of all B19V RNA transcripts, see Fig 9A), when transfected in HeLa cells.

573 The authors hypothesized that this effect was indirect, since the promoter is localized in the 574 nucleus. The study also reported that expression of the $X$ protein into HeLa cells resulted in no 575 visible change. 
578 An earlier work on PARV4 [10] hypothesized that the ARF1/X protein was homologous to the

579 SAT protein, another short, transmembrane protein encoded in the +1 frame of the VP1 gene in the 580 genus protoparvovirus [49]. However, SAT and X cannot be homologous (i.e. have a common

581 origin), since SAT is encoded by the N-terminus of VP2, immediately downstream of the region 582 encoding the PLA2 domain (our observations), unlike the $\mathrm{X}$ protein, which overlaps the $\mathrm{N}$-terminus 583 of PLA2 (see Figs 3 and 4).

\section{The X ORF most probably originated by overprinting the VP1 ORF}

Most overlapping gene pairs originate by overprinting, a process in which substitutions in an ancestral reading frame enable the expression of a second reading frame (the novel frame), while preserving the expression of the first frame $[50,51]$. The ancestral frame can be identified by its phylogenetic distribution (the ORF with the widest distribution is most probably the ancestral one) $[50,52]$, or by their codon usage [53] if both frames have the same phylogenetic distribution. reading frame, since a PLA2 domain is found not only in most Parvoviridae, but also in a wide variety of metazoans and plants [54], whereas the $\mathrm{X}$ protein is found only in erythro- and tetraparvoviruses. Therefore, the $\mathrm{X}$ protein must have originated by overprinting the region encoding the PLA2 domain in the VP1 frame, in the putative common ancestor of erythro- and tetraparvoviruses.

599 Two species differ from other erythro- and tetraparvoviruses in the coding strategy in their VP1 600 gene: bovine parvovirus 3 (bPARV3) and porcine parvovirus 2 (pPARV2). encodes an X-like protein in a location similar to that of other erythroparvoviruses, i.e. upstream of the VP1/VP2 boundary (Fig 7). Assuming that the ancestor of bPARV3 had a PLA2 domain like all 
605 either 1) the bPARV3 X-like ORF is unrelated to the X ORF, and originated in bPARV3 by

606 overprinting VP1 after it had lost the PLA2 domain ("convergent evolution"); or 2) the X-like ORF is

607 descended from the X ORF, and persisted in the viral genome even when substitutions

608 accumulated in the region encoding the PLA2 domain to the point of erasing its sequence signature

609 ("divergent evolution"). In the second scenario, constraints imposed by PLA2 on the X-like ORF

610 would have disappeared, which would explain why the X-like protein is divergent in sequence.

pPARV2 is currently classified as a tetraparvovirus, though some authors have noticed it

612 forms a separate sublineage [31]. pPARV2 encodes a PLA2 domain but no X protein. However, it

613 may encode a "Z protein" immediately upstream of PLA2 (Fig 8). Again, this observation suggests

614 two hypotheses: 1) either the Z ORF is unrelated to the X ORF; or 2) it is descended from the $\mathrm{X}$

615 ORF but lost the 3 ' region that encodes the transmembrane region and overlaps PLA2.

616

\section{Conclusion}

Like most research, our work raises more questions than it answers. One that we find of

particular interest is whether, and how, the R3' transcript of B19V (Fig 9A) avoids translation of a truncated form of VP1, which would presumably trigger Non-stop decay $[55,56]$ (for a review, see [44]), and degradation of R3'. We are not sure whether this question has been raised before.

On another note, our findings suggest that numerous proteins encoded by overlapping

624 genes remain to be discovered in single-stranded DNA viruses (we know of at least one potential 625 such case already flagged by sequence analyses, in human bocavirus [57]). Indeed, while a 626 systematic effort has been made to discover overlapping genes in RNA viruses [15], this has not yet 627 been the case in DNA viruses. We therefore recommend that readers analyze their own genome of 628 interest using the tools and strategies presented here. This is perfectly feasible for bench virologists

629 lacking computing skills (like the author), since the present work required no programming; all 630 analyses were done using web-based, relatively user-friendly programs (see Methods) on a 631 standard laptop computer. In addition, no virologist was harmed during the work. 


\section{Materials and Methods}

\section{Sequence collection}

We collected the coding sequences of VP1 for all isolates of viral species investigated here

by using Blastn [58] against Genbank (30 ${ }^{\text {th }}$ July 2019) on the reference sequence of each species.

637 We retained sequences with $>75 \%$ nucleotide similarity over $90 \%$ of the length of the query (i.e.

$63890 \%$ coverage). We removed duplicate sequences, sequences containing insertions or deletions 639 longer than 50 nucleotides with respect to the reference sequence, or those marked as "synthetic" 640 sequences.

\section{Nucleotide sequence alignment and analysis}

To generate codon-respecting alignments based on the coding sequence of VP1, we used the program TranslatorX [26] with the "Muscle" option. The resulting codon-based alignments are in 644 the S1-S4 Alignments.

\section{Analysis of Kozak consensus sequences of potential AUG start codons}

Kozak sequences surrounding an AUG start codon can direct translation from this AUG with

varying degrees of strength [42]. The most important factor is the presence of a purine (A or $G) 3$

nucleotides upstream of the AUG start codon, and of a $G$ (or less favourably an $U$ ) immediately after the AUG. For the ORFs considered here, we classified Kozak sequences of potential AUG start codons in 4 categories, as in a recent exhaustive analysis in vertebrates [42]: 1) "optimal" Kozak

(A/G)NNAUGG, where $\mathrm{N}$ is any nucleotide; 3) "moderate" match the consensus

$(A / G)(A / C)(A / C) \underline{A \cup G}(G / U)$; finally 4$)$ "weak" Kozak sequences do not match any of these consensus sequences [42].

\section{Detection of regions with lower synonymous substitution rate}


65945 codons provides better sensitivity, which helped us map the precise boundaries of the regions 660 identified. We present Synplot2 plots computed with a window of either 25 or 45 codons, depending 661 on which window size better shows the regions identified. The boundaries of these regions were 662 always mapped with a window of 45 codons.

\section{Protein sequence alignment and domain identification}

All protein sequence alignments are presented using Jalview [59] with the ClustalX colouring scheme [60]. We carried out phylogenetic analyses using phylogeny.fr [61] with default options. To add unaligned sequences into a reference alignment, we used MAFFT with the --add option [30]. The S5 alignment contains the sequence alignment of all $\mathrm{X}$ and $\mathrm{X}$-like proteins. We used HHpred 668 [28] to identify protein domains.

\section{Prediction of protein structural features}

We used MetaDisorder [62] to predict disordered regions, in accordance with the principles described in [63], and DeepCoil [64] to predict coiled-coil regions. We used SEG [32], called via the ANNIE web server [65], to detect protein regions of low or medium sequence complexity, with parameters 45/3.75/3.4.

We used two complementary methods to detect reliably predicted transmembrane segments, as explained in [66]. First, we compared the predictions of several transmembrane prediction programs on a single protein, for each protein ("vertical approach"), by using ANNIE [65].

678 ("horizontal" approach).

\section{Supporting information captions}

S1 Fig. Multiple sequence alignment of the tetraparvovirus ARF2 ORF. 
684 Conventions are the same as in Fig 5. N-terminal Methionines that could correspond to an AUG 685 start codon are indicated in bold. In other tetraparvoviruses more distant from PARV4 (not shown 686 here) the ARF2 ORF is interrupted by stop codons.

688 S2 Fig. Alignment of the X-like protein of bovine parvovirus 3 with the reference alignment of 689 the $\mathrm{X}$ protein of erythro- and tetraparvoviruses.

690 The corresponding alignment in text format is provided in S5 Alignment.

691 We used MAFFT-add to align the X-like protein of bovine parvovirus 3 with the reference alignment 692 of the X protein of erythro- and tetraparvoviruses, derived from the alignment of the PLA2 domain, 693 and presented in Fig 6 (see main text). The two positions strictly conserved in all X proteins and in 694 the X-like protein are indicated. Notice that a third position, towards the C-terminus, containing a 695 Glycine (G73 in B19V), appears to be also conserved; however this region of the alignment is not 696 reliable, owing to the presence of gaps and to its high variability. The corresponding alignment in 697 text format is in S5 Alignment.

699 S3 Fig. Sequence of the Z protein of porcine parvovirus 2.

700 Conventions are the same as in Fig 5.

701 S1 Alignment. Codon alignment of all B19V VP1 coding sequences

S2 Alignment. Codon alignment of all PARV4 VP1 coding sequences

S3 Alignment. Codon alignment of all bPARV3 VP1 coding sequences

S4 Alignment. Codon alignment of all pPARV2 VP1 coding sequences

S5 Alignment. Alignment of the X-like protein of bPARV3 with the reference alignment of the $X$ proteins of erythroparvoviruses and tetraparvoviruses, in text format.

707 The corresponding alignment in Jalview format is shown in S2 Fig.

708 S6 Alignment. The X ORF has a potential AUG start codon in all erythro- and 709 tetraparvoviruses 
713 We gratefully acknowledge AE Firth for useful advice in using Synplot2 and for help with preparing

714 the Synplot2 Figs, and S. Courtès, J Qiu and G. Gallinella for commenting on the manuscript. We

715 thank all the authors of the user-friendly, web-based software without whom this work would not

716 have been possible. The author would like to thank the Marie Skłodowska-Curie European

717 programme for not funding his research project and thereby allowing him to lead a fulfilling life,

718 doing research as a rewarding hobby.

719

720

721

722

723

724

725

726

727

728

729

730

731

732

733

734

735

736

737

738

739

740

741

742

743

744

745

746

747

\section{References}

1. Söderlund-Venermo M. Emerging Human Parvoviruses: The Rocky Road to Fame. Annu Rev Virol. 2019;6: annurev-virology-092818-015803. doi:10.1146/annurev-virology-092818-015803

2. Kailasan S, Agbandje-McKenna M, Parrish CR. Parvovirus Family Conundrum: What Makes a Killer? Annu Rev Virol. 2015;2: 425-450. doi:10.1146/annurev-virology-100114-055150

3. Cotmore SF, Tattersall P. Parvoviruses: Small Does Not Mean Simple. Annu Rev Virol. 2014;1: 517-537. doi:10.1146/annurev-virology-031413-085444

4. Ganaie SS, Qiu J. Recent Advances in Replication and Infection of Human Parvovirus B19. Front Cell Infect Microbiol. 2018;8: 166. doi:10.3389/fcimb.2018.00166

5. Matthews PC, Sharp C, Simmonds P, Klenerman P. Human parvovirus 4 'PARV4' remains elusive despite a decade of study. F1000Res. 2017;6: 82. doi:10.12688/f1000research.9828.1

6. Luo W, Astell CR. A Novel Protein Encoded by Small RNAs of Parvovirus B19. Virology. 1993;195: 448-455. doi:10.1006/viro.1993.1395

7. St Amand J, Beard C, Humphries K, Astell CR. Analysis of splice junctions and in vitro and in vivo translation potential of the small, abundant B19 parvovirus RNAs. Virology. 1991;183: 133-142. doi:10.1016/0042-6822(91)90126-v

8. St Amand J, Astell CR. Identification and characterization of a family of 11-kDa proteins encoded by the human parvovirus B19. Virology. 1993;192: 121-131. doi:10.1006/viro.1993.1014

9. Zhi N, Mills IP, Lu J, Wong S, Filippone C, Brown KE. Molecular and functional analyses of a human parvovirus B19 infectious clone demonstrates essential roles for NS1, VP1, and the 11 kilodalton protein in virus replication and infectivity. J Virol. 2006;80: 5941-5950. doi:10.1128/JVI.02430-05

10. Simmonds P, Douglas J, Bestetti G, Longhi E, Antinori S, Parravicini C, et al. A third genotype of the human parvovirus PARV4 in sub-Saharan Africa. J Gen Virol. 2008;89: 2299-2302. doi:10.1099/vir.0.2008/001180-0 
748

11. Pavesi A, Vianelli A, Chirico N, Bao Y, Blinkova O, Belshaw R, et al. Overlapping genes and the proteins they encode differ significantly in their sequence composition from nonoverlapping genes. PLoS ONE. 2018;13: e0202513. doi:10.1371/journal.pone.0202513

12. Firth $\mathrm{AE}$, Brown $\mathrm{CM}$. Detecting overlapping coding sequences with pairwise alignments. Bioinformatics. 2005;21: 282-292. doi:10.1093/bioinformatics/bti007

13. Sabath N, Landan G, Graur D. A method for the simultaneous estimation of selection intensities in overlapping genes. PLoS ONE. 2008;3: e3996. doi:10.1371/journal.pone.0003996

14. Norja P, Eis-Hübinger AM, Söderlund-Venermo M, Hedman K, Simmonds P. Rapid sequence change and geographical spread of human parvovirus B19: comparison of B19 virus evolution in acute and persistent infections. J Virol. 2008;82: 6427-6433. doi:10.1128/JVI.00471-08

15. Firth AE. Mapping overlapping functional elements embedded within the protein-coding regions of RNA viruses. Nucleic Acids Res. 2014;42: 12425-12439. doi:10.1093/nar/gku981

16. Chung BY-W, Miller WA, Atkins JF, Firth AE. An overlapping essential gene in the Potyviridae. Proc Natl Acad Sci USA. 2008;105: 5897-5902. doi:10.1073/pnas.0800468105

17. Jagger BW, Wise HM, Kash JC, Walters K-A, Wills NM, Xiao Y-L, et al. An overlapping protein-coding region in influenza $A$ virus segment 3 modulates the host response. Science. 2012;337: 199-204. doi:10.1126/science.1222213

18. Ratinier M, Caporale M, Golder M, Franzoni G, Allan K, Nunes SF, et al. Identification and characterization of a novel non-structural protein of bluetongue virus. PLoS Pathog. 2011;7: e1002477. doi:10.1371/journal.ppat.1002477

19. Zádori Z, Szelei J, Lacoste MC, Li Y, Gariépy S, Raymond P, et al. A viral phospholipase A2 is required for parvovirus infectivity. Dev Cell. 2001;1: 291-302.

20. Dorsch S, Liebisch G, Kaufmann B, von Landenberg P, Hoffmann JH, Drobnik W, et al. The VP1 unique region of parvovirus B19 and its constituent phospholipase A2-like activity. J Virol. 2002;76: 2014-2018. doi:10.1128/jvi.76.4.2014-2018.2002

21. Gruber AR, Neubock R, Hofacker IL, Washietl S. The RNAz web server: prediction of thermodynamically stable and evolutionarily conserved RNA structures. Nucleic Acids Research. 2007;35: W335-W338. doi:10.1093/nar/gkm222

22. Washietl S, L. Hofacker I. Identifying Structural Noncoding RNAs Using RNAz. In: Baxevanis AD, Davison DB, Page RDM, Petsko GA, Stein LD, Stormo GD, editors. Current Protocols in Bioinformatics. Hoboken, NJ, USA: John Wiley \& Sons, Inc.; 2007. p. bi1207s19. doi:10.1002/0471250953.bi1207s19

23. Leisi R, Di Tommaso C, Kempf C, Ros C. The Receptor-Binding Domain in the VP1u Region of Parvovirus B19. Viruses. 2016;8: 61. doi:10.3390/v8030061

24. Baker JA, Wong W-C, Eisenhaber B, Warwicker J, Eisenhaber F. Charged residues next to transmembrane regions revisited: "Positive-inside rule" is complemented by the "negative inside depletion/outside enrichment rule." BMC Biol. 2017;15: 66. doi:10.1186/s12915-0170404-4 
25. Wong W-C, Maurer-Stroh S, Eisenhaber F. Not all transmembrane helices are born equal: Towards the extension of the sequence homology concept to membrane proteins. Biol Direct. 2011;6: 57. doi:10.1186/1745-6150-6-57

26. Abascal F, Zardoya R, Telford MJ. TranslatorX: multiple alignment of nucleotide sequences guided by amino acid translations. Nucleic Acids Res. 2010;38: W7-13. doi:10.1093/nar/gkq291

27. Lo MK, Søgaard TM, Karlin DG. Evolution and structural organization of the $C$ proteins of paramyxovirinae. PLoS ONE. 2014;9: e90003. doi:10.1371/journal.pone.0090003

28. Söding J, Biegert A, Lupas AN. The HHpred interactive server for protein homology detection and structure prediction. Nucleic Acids Res. 2005;33: W244-248. doi:10.1093/nar/gki408

29. Allander T, Emerson SU, Engle RE, Purcell RH, Bukh J. A virus discovery method incorporating DNase treatment and its application to the identification of two bovine parvovirus species. Proc Natl Acad Sci USA. 2001;98: 11609-11614. doi:10.1073/pnas.211424698

30. Katoh K, Frith MC. Adding unaligned sequences into an existing alignment using MAFFT and LAST. Bioinformatics. 2012;28: 3144-3146. doi:10.1093/bioinformatics/bts578

31. Wang F, Wei Y, Zhu C, Huang X, Xu Y, Yu L, et al. Novel parvovirus sublineage in the family of Parvoviridae. Virus Genes. 2010;41: 305-308. doi:10.1007/s11262-010-0506-3

32. Wootton JC. Non-globular domains in protein sequences: automated segmentation using complexity measures. Comput Chem. 1994;18: 269-285.

33. Yoto Y, Qiu J, Pintel DJ. Identification and characterization of two internal cleavage and polyadenylation sites of parvovirus B19 RNA. J Virol. 2006;80: 1604-1609. doi:10.1128/JVI.80.3.1604-1609.2006

34. Ozawa K, Ayub J, Hao YS, Kurtzman G, Shimada T, Young N. Novel transcription map for the B19 (human) pathogenic parvovirus. J Virol. 1987;61: 2395-2406.

35. Bua G, Manaresi E, Bonvicini F, Gallinella G. Parvovirus B19 Replication and Expression in Differentiating Erythroid Progenitor Cells. Qiu J, editor. PLoS ONE. 2016;11: e0148547. doi:10.1371/journal.pone.0148547

36. Lou S, Xu B, Huang Q, Zhi N, Cheng F, Wong S, et al. Molecular characterization of the newly identified human parvovirus 4 in the family Parvoviridae. Virology. 2012;422: 59-69. doi:10.1016/j.virol.2011.09.033

37. Liu Z, Qiu J, Cheng F, Chu Y, Yoto Y, O'Sullivan MG, et al. Comparison of the transcription profile of simian parvovirus with that of the human erythrovirus B19 reveals a number of unique features. J Virol. 2004;78: 12929-12939. doi:10.1128/JVI.78.23.12929-12939.2004

38. Chen Z, Chen AY, Cheng F, Qiu J. Chipmunk parvovirus is distinct from members in the genus Erythrovirus of the family Parvoviridae. PLoS ONE. 2010;5: e15113. doi:10.1371/journal.pone.0015113

39. Firth AE, Brierley I. Non-canonical translation in RNA viruses. Journal of General Virology. 2012;93: 1385-1409. doi:10.1099/vir.0.042499-0

40. Baralle M, Baralle FE. The splicing code. Biosystems. 2018;164: 39-48. doi:10.1016/j.biosystems.2017.11.002 
827

828

829

830

831

832

833

834

835

836

837

838

839

840

841

842

843

844

845

846

847

848

849

850

851

852

853

854

855

856

857

858

859

860

861

862

863

864

865

866

41. Gupta A, Bansal M. RNA-mediated translation regulation in viral genomes: computational advances in the recognition of sequences and structures. Briefings in Bioinformatics. 2019; bbz054. doi:10.1093/bib/bbz054

42. Hernández G, Osnaya VG, Pérez-Martínez X. Conservation and Variability of the AUG Initiation Codon Context in Eukaryotes. Trends in Biochemical Sciences. 2019; S096800041930146X. doi:10.1016/j.tibs.2019.07.001

43. Ozawa K, Ayub J, Young N. Translational regulation of B19 parvovirus capsid protein production by multiple upstream AUG triplets. J Biol Chem. 1988;263: 10922-10926.

44. Karamyshev AL, Karamysheva ZN. Lost in Translation: Ribosome-Associated mRNA and Protein Quality Controls. Front Genet. 2018;9: 431. doi:10.3389/fgene.2018.00431

45. Shade RO, Blundell MC, Cotmore SF, Tattersall P, Astell CR. Nucleotide sequence and genome organization of human parvovirus B19 isolated from the serum of a child during aplastic crisis. J Virol. 1986;58: 921-936.

46. Zhi N, Wan Z, Liu X, Wong S, Kim DJ, Young NS, et al. Codon optimization of human parvovirus B19 capsid genes greatly increases their expression in nonpermissive cells. J Virol. 2010;84: 13059-13062. doi:10.1128/JVI.00912-10

47. Filippone C, Zhi N, Wong S, Lu J, Kajigaya S, Gallinella G, et al. VP1u phospholipase activity is critical for infectivity of full-length parvovirus B19 genomic clones. Virology. 2008;374: 444452. doi:10.1016/j.virol.2008.01.002

48. Dong $\mathrm{Y}$, Huang $\mathrm{Y}$, Wang $\mathrm{Y}, \mathrm{Xu} \mathrm{P}$, Yang $\mathrm{Y}$, Liu K, et al. The effects of the $11 \mathrm{kDa}$ protein and the putative $X$ protein on the 6 promoter activity of Parvovirus B19 in Hela cells. Virus Genes. 2013;46: 167-169. doi:10.1007/s11262-012-0839-1

49. Zádori Z, Szelei J, Tijssen P. SAT: a late NS protein of porcine parvovirus. J Virol. 2005;79: 13129-13138. doi:10.1128/JVI.79.20.13129-13138.2005

50. Rancurel C, Khosravi M, Dunker AK, Romero PR, Karlin D. Overlapping genes produce proteins with unusual sequence properties and offer insight into de novo protein creation. $J$ Virol. 2009;83: 10719-10736. doi:10.1128/JVI.00595-09

51. Keese PK, Gibbs A. Origins of genes: "big bang" or continuous creation? Proc Natl Acad Sci USA. 1992;89: 9489-9493. doi:10.1073/pnas.89.20.9489

52. Sabath N, Wagner A, Karlin D. Evolution of viral proteins originated de novo by overprinting. Mol Biol Evol. 2012;29: 3767-3780. doi:10.1093/molbev/mss179

53. Pavesi A, Magiorkinis G, Karlin DG. Viral proteins originated de novo by overprinting can be identified by codon usage: application to the "gene nursery" of Deltaretroviruses. PLoS Comput Biol. 2013;9: e1003162. doi:10.1371/journal.pcbi.1003162

54. Schaloske $\mathrm{RH}$, Dennis EA. The phospholipase A2 superfamily and its group numbering system. Biochimica et Biophysica Acta (BBA) - Molecular and Cell Biology of Lipids. 2006;1761: 1246-1259. doi:10.1016/j.bbalip.2006.07.011

55. Frischmeyer PA, van Hoof A, O'Donnell K, Guerrerio AL, Parker R, Dietz HC. An mRNA surveillance mechanism that eliminates transcripts lacking termination codons. Science. 2002;295: 2258-2261. doi:10.1126/science.1067338 
867 56. van Hoof A, Frischmeyer PA, Dietz HC, Parker R. Exosome-mediated recognition and degradation of mRNAs lacking a termination codon. Science. 2002;295: 2262-2264. doi:10.1126/science.1067272

57. Sealfon RS, Lin MF, Jungreis I, Wolf MY, Kellis M, Sabeti PC. FRESCo: finding regions of excess synonymous constraint in diverse viruses. Genome Biol. 2015;16: 38. doi:10.1186/s13059-015-0603-7

58. Altschul SF, Madden TL, Schäffer AA, Zhang J, Zhang Z, Miller W, et al. Gapped BLAST and PSI-BLAST: a new generation of protein database search programs. Nucleic Acids Res. 1997;25: 3389-3402. doi:10.1093/nar/25.17.3389

59. Waterhouse AM, Procter JB, Martin DMA, Clamp M, Barton GJ. Jalview Version 2--a multiple sequence alignment editor and analysis workbench. Bioinformatics. 2009;25: 1189-1191. doi:10.1093/bioinformatics/btp033

60. Procter JB, Thompson J, Letunic I, Creevey C, Jossinet F, Barton GJ. Visualization of multiple alignments, phylogenies and gene family evolution. Nat Methods. 2010;7: S16-25. doi:10.1038/nmeth. 1434

61. Dereeper A, Guignon V, Blanc G, Audic S, Buffet S, Chevenet F, et al. Phylogeny.fr: robust phylogenetic analysis for the non-specialist. Nucleic Acids Res. 2008;36: W465-469. doi:10.1093/nar/gkn180

62. Kozlowski LP, Bujnicki JM. MetaDisorder: a meta-server for the prediction of intrinsic disorder in proteins. BMC Bioinformatics. 2012;13: 111. doi:10.1186/1471-2105-13-111

63. Ferron F, Longhi S, Canard B, Karlin D. A practical overview of protein disorder prediction methods. Proteins. 2006;65: 1-14. doi:10.1002/prot.21075

64. Ludwiczak J, Winski A, Szczepaniak K, Alva V, Dunin-Horkawicz S. DeepCoil-a fast and accurate prediction of coiled-coil domains in protein sequences. Bioinformatics. 2019;35: 2790-2795. doi:10.1093/bioinformatics/bty1062

65. Ooi HS, Kwo CY, Wildpaner M, Sirota FL, Eisenhaber B, Maurer-Stroh S, et al. ANNIE: integrated de novo protein sequence annotation. Nucleic Acids Res. 2009;37: W435-440. doi:10.1093/nar/gkp254

66. Kuchibhatla DB, Sherman WA, Chung BYW, Cook S, Schneider G, Eisenhaber B, et al. Powerful sequence similarity search methods and in-depth manual analyses can identify remote homologs in many apparently "orphan" viral proteins. J Virol. 2014;88: 10-20. doi:10.1128/JVI.02595-13

67. Floden EW, Tommaso PD, Chatzou M, Magis C, Notredame C, Chang J-M. PSI/TM-Coffee: a web server for fast and accurate multiple sequence alignments of regular and transmembrane proteins using homology extension on reduced databases. Nucleic Acids Res. 2016;44: W339343. doi:10.1093/nar/gkw300 